\title{
¿ESPAÑA EN LA ENCRUCIJADA? \\ Consideraciones sobre el cambio de ciclo migratorio
}

\author{
SPAIN AT THE TURNING POINT? \\ Considerations on the change of migratory cycle
}

DAVID REHER dreher@geps.es

Universidad Complutense de Madrid y Grupo de Estudios "Población y Sociedad". España

Miguel Requena mrequena@poli.uned.es

UNED y Grupo de Estudios "Población y Sociedad". España

Alberto Sanz asanzgimeno@geps.es

Universidad Complutense de Madrid y Grupo de Estudios "Población y Sociedad". España

\section{RESUMEN}

El presente trabajo revisa la experiencia migratoria en España durante los últimos ciento cincuenta años para contextualizar históricamente la reciente explosión de inmigrantes que se ha producido a la vuelta del nuevo siglo y el cambio de ciclo migratorio que el país ha experimentado con ocasión de la actual crisis económica. El análisis del calendario, las características principales y los factores explicativos básicos de la reciente explosión migratoria suministran los elementos para hacer un pronóstico razonable sobre el futuro previsible de las migraciones en España en los próximos años.

\section{Palabras Clave}

Ciclo migratorio, Crisis económica, Inmigración.

\section{SUMMARY}

This paper reviews the Spanish migratory experience throughout the last hundred and fifty years in order to contextualize from a historical point of view the recent immigration boom that has taken place at the turn of the new century and the change of migratory cycle that the county has undergone under the impact of the current economic crisis. The analysis of the calendar, the main features and the key explanatory factors that underlie the recent migratory boom provides the elements to make a sound forecast about the foreseeable future of migrations in Spain in next years.

\section{KEYWORDS}

Economic Crisis, Immigration, Migratory Cycle. 


\section{INTRODUCCIÓN}

La intensidad de las migraciones recientes en España ha hecho de ellas un tema estrella de la investigación social y una piedra angular de muchas de las preocupaciones políticas y sociales actualmente existentes en el país. El cambio de tendencia producida en los últimos dos años - cuyo alcance dista mucho de ser claro pero que supone sin duda el final de la época de las llegadas masivas y desbordantes de inmigrantes del período 2000-2007- no ha alterado la relevancia del tema para la sociedad española. Uno de los resultados científicos de este persistente interés ha sido la realización de la Encuesta Nacional de Inmigrantes-2007, desarrollada por el Instituto Nacional de Estadística (INE) a propuesta de, y en colaboración con, un grupo de investigadores de la Universidad Complutense y de la Universidad Nacional de Educación a Distancia (UNED) inserto dentro del Grupo de Estudios Población y Sociedad (GEPS). Buena parte de los estudios incluidos en este número de la Revista Internacional de Sociología (RIS) se basan precisamente en esta gran encuesta y suponen una profundización y ampliación de la explotación de la misma que, hasta el momento, ha generado un considerable número de publicaciones (Reher et al. 2008; Reher y Requena 2008; Reher y Requena 2009a; Reher y Requena 2009b).

El propósito del presente artículo no es, ni intenta ser, una glosa de los artículos que aparecen en el número. Lo que en cambio pretendemos aquí es enmarcar esta época a todas luces excepcional en materia migratoria en una perspectiva más amplia; perspectiva que, por un lado, se adentra en el terreno de nuestra historia y, por otro, avanza una proyección de los escenarios posibles en los que podría desenvolverse el futuro de las migraciones en España. Dicho de otra forma $-y$ con un lenguaje menos académicopretendemos insertar el boom migratorio español dentro de una especie de emparedado analítico que incorpore tanto la experiencia conocida del pasado como el futuro previsible. Hay dos razones fundamentales que aconsejan adoptar una postura de esta naturaleza. Primera, España es un país que tiene una amplia historia migratoria dentro de la que cabe ubicar la oleada de inmigración de los años 2000 como un episodio nuevo, es decir, con algunas características novedosas que, sin embargo, se inscriben en una dinámica ya conocida. En este sentido, un buen conocimiento de la historia hace mucho por contextualizar adecuadamente las migraciones recientes en España y permite anticipar de manera aproximada como se irán desarrollado sus efectos profundos sobre la sociedad y la economía nacionales. Es claro que dichos efectos tenderían a pasar desapercibidos si el análisis se circunscribiera a una perspectiva temporalmente más inmediata. Segunda, es indudable que estamos adentrándonos en una época nueva de perfiles inciertos. No obstante, aun reconociendo la imposibilidad de predecir el futuro, la verdad es que obran en nuestro poder datos - no opiniones - que permiten ver al menos de forma aproximada algunos de los aspectos claves para los años venideros. Como científicos sociales es nuestra obligación hacer uso de nuestro conocimiento del pasado y del presente a fin de arrojar algo de luz sobre el camino por recorrer. 
En esta línea, en el presente trabajo revisamos sucintamente la experiencia migratoria de nuestro país durante el último siglo y medio. A continuación, analizamos la explosión migratoria que ha vivido España a la vuelta del nuevo siglo, para lo cual prestamos especial atención a su calendario, sus características principales y sus principales factores explicativos. Nos ocupamos, después, del cambio de ciclo migratorio que el país ha experimentado con ocasión de la reciente crisis económica. Con la debida prudencia que hace al caso, abordamos, por último, el futuro previsible de las migraciones en nuestro país a la luz de la información disponible.

\section{SigLO Y MEdiO dE HISTORIA MIGRATORIA EN ESPAÑA}

Las migraciones no son un fenómeno nuevo en España. Ciñéndonos tan sólo a la historia reciente, en los últimos 150 años las migraciones, tanto internas como internacionales, han tenido una gran importancia para el desarrollo del país. La gran mayoría de estos procesos ha tenido a españoles como emigrantes; es decir, salían de su país en busca de una vida mejor o salían de su pueblo o su región también en busca de un futuro mejor. Lo que distingue los procesos más recientes es precisamente el hecho de que España se haya convertido, en el plazo de unos pocos años, en un destino clave para inmigrantes de diversos orígenes.

Se pueden apreciar en el siglo XX tres grandes oleadas migratorias, cada una de ellas con causas y efectos diferentes, pero todas ellas con profundas implicaciones económicas y sociales. Durante la segunda mitad del siglo XIX, España era un país básicamente rural, con una población con un bajo nivel de educación y niveles de movilidad de largo recorrido relativamente reducidos. Existen indicios de que durante las décadas centrales del siglo el rápido crecimiento de la población contribuyó a una disminución del nivel de vida de la población, tal y como indican los aumentos en diversos indicadores de mortalidad y una disminución de la estatura en las décadas centrales del siglo (Martínez Carrión 2002). Como es sabido, los incipientes centros de dinamismo económico no se ubicaban en las zonas rurales, sino en algunos centros urbanos y regiones, tales como Madrid, Cataluña (el litoral), el País Vasco (Guipúzcoa y Vizcaya), Valencia, Asturias, etc., que se convirtieron en poderosos focos de atracción para una población que buscaba nuevas y mejores oportunidades de vida.

Esta combinación de circunstancias produjo una doble corriente migratoria. Una de ellas era de sentido interno, desde el campo hacia la ciudad o entre regiones. Se trataba de una migración tradicional, histórica. Existen indicios de una aceleración de estas corrientes en la segunda mitad del siglo XIX y en las primeras décadas del XX (Silvestre 2005). Nunca llegaron a ser tan importantes como las corrientes migratorias transoceánicas, aunque tampoco eran despreciables. Se orientaban hacia ciertos centros urbanos caracterizados por su dinamismo económico y, además, contribuían a una aceleración en los procesos de urbanización en marcha. Pese a que es muy difícil medir la intensidad de estas corrientes, sus 
efectos diferenciales en distintas regiones están fuera de toda duda. ${ }^{1}$ La progresiva industrialización de España habría sido a todas luces imposible sin estas corrientes migratorias.

Paralelamente se produjo una poderosísima corriente migratoria con destino sobre todo al continente americano, aunque también se orientó hacia el norte de África e incluso hacia Francia. Esta corriente empezó a cobrar intensidad en los años 1870-80 y duró aproximadamente hasta 1930. Tuvo su punto culminante en la década anterior a la Primera Guerra Mundial. En realidad, fue un fenómeno que afectó a todo el continente europeo, aunque la intensidad media en España fue menor que en países fuertemente emigratorios como Irlanda, Escocia, Portugal o Italia (Baines 1991).

Estas corrientes tuvieron implicaciones económicas, políticas, sociales y culturales enormes para las zonas receptoras, sobre todo para los países de destino preferido (de los españoles) como Argentina, Uruguay, Brasil o Cuba (Sánchez Alonso, 1995; 2000a; $2000 \mathrm{~b})$. En las zonas emisoras presentaron efectos tanto positivos como negativos. Entre los primeros, ayudaron a eliminar excedentes de población en el mundo rural; constituyeron, asimismo, una importante fuente de divisas y de ahorro que parecen haber sido invertidas, al menos en una primera fase, en las zonas de origen, aunque sobre este aspecto de la migración conocemos menos de lo que debiéramos. Los mismos retornados también colaboraron activamente en la promoción de sus zonas de origen. ${ }^{2}$ En los casos en los que se dio una migración verdaderamente de ida y vuelta - llamada golondrina-, más habitual en las corrientes orientadas hacía el norte de África pero también presente en algunas migraciones transoceánicas, la relación económica habrá sido mucho más directa. Entre las consecuencias negativas de estas corrientes migratorias cabe citar la pérdida de potencial humano, en especial considerando que la emigración suele ser selectiva para los más capaces, que dejó algunas zonas españolas con serias desventajas de cara a su futuro desarrollo económico debido a los desajustes en la estructura por edad y sexo de la población en edad laboral. Esta desventaja fue especialmente evidente en las zonas de Galicia y Asturias donde la corriente emigratoria llegó a ser más intensa. $^{3}$

La época de las grandes migraciones transoceánicas terminó de forma bastante abrupta a raíz de la Gran Depresión, la Guerra Civil y la Segunda Guerra Mundial y la progresiva imposición de restricciones a la inmigración por parte de los países receptores. De hecho, el período que media aproximadamente entre 1930 y 1950 no se distingue por corrientes migratorias fuertes, ni internas ni internacionales, en España. Ello no quiere decir que no se produjeran ambos tipos de migración, sino que fueron menos intensos que en épocas anteriores. La excepción

\footnotetext{
${ }^{1}$ Dos ejemplos de estas corrientes serían los burgaleses que llegaron a la ría de Bilbao o los alcoyanos a Barcelona y su entorno.

"Véase, por ejemplo, el impacto de los "indianos" (los retornados de América) sobre sus zonas de origen en todo el norte de España.

${ }^{3}$ En algunas comarcas del interior de Galicia, se estima que entre 1900 y 1910, por ejemplo, se marcharon cerca del 50 por cien o más de los varones jóvenes en edad laboral (que tenían, por ejemplo, 10-14 años en 1900 y 20-24 en 1910).
} 
aquí, claro está, son las migraciones que tuvieron lugar a raíz de la Guerra Civil y sus secuelas durante los años 40 . Estas corrientes, por dramáticas y tristes que fueran, nunca alcanzaron la intensidad que caracterizó épocas anteriores.

La segunda oleada migratoria fue, con toda probabilidad, bastante más intensa que la primera y tuvo implicaciones económicas y sociales incluso mayores. De nuevo, la desencadenó una considerable presión demográfica sobre los recursos disponibles en el mundo rural que se debió, a su vez, al rapidísimo crecimiento de la población en dichas zonas durante los 15-20 años posteriores a la Guerra Civil. Ese crecimiento obedeció en parte a la gran caída de la mortalidad a los primeros años de vida - que se aceleró precisamente durante ese período - combinada con un ligero aumento de la fecundidad. Tal y como había pasado con las migraciones producidas entre 1880 y 1930 , esta segunda gran oleada migratoria consistió en una doble corriente, una de migración interna y otro externa. La migración española hacia Europa fue, por regla general, una migración temporal y estuvo acompañada por otra corriente migratoria intensísima hacia ciertas regiones y zonas urbanas del país. En estos años también se produjo otro flujo migratorio, esta vez bastante más débil, hacia ciertas zonas de Sudamérica.

Se trataba de corrientes migratorias que arrancaron en la década de los años cincuenta, sobre todo en su segunda mitad, y que cobran mayor intensidad durante la segunda mitad de los años sesenta, disminuyendo rápidamente a partir de 1973-75. Los españoles llegaron a ser numerosísimos en Europa, superando el millón de personas en algunos momentos. No obstante, con toda probabilidad la migración interna fue bastante más intensa. La finalización abrupta de los flujos hacia Europa a raíz de la crisis económica de mediados de los años setenta, junto al similar declive de las migraciones internas, marcaron el punto final de uno de los procesos sociales de mayor envergadura experimentados por España en todo el siglo XX.

Cuando volvieron a España desde Europa, los emigrantes españoles se afincaron principalmente en las zonas urbanas del país, contribuyendo así al rapidísimo proceso de urbanización que tuvo lugar en España entre 1960 y 1980. Las regiones emigratorias eran mayoritariamente zonas rurales en todo el país, aunque esta vez, a diferencia de lo ocurrido con la primera oleada migratoria, se concentraron sobre todo en la zona central (ambas mesetas) y en Andalucía. Las regiones tradicionalmente emigratorias en España, fundamentalmente las situadas en la cornisa cantábrica —con la excepción de Galicia-, participaron menos esta vez, a causa de la progresiva concentración en dichas regiones del crecimiento industrial del país.

Este proceso migratorio tuvo enormes consecuencias -más positivas que negativas en su conjunto- que fueron un elemento nada despreciable en la rápida modernización de la sociedad española ocurrida durante la época. Al igual que las grandes migraciones transoceánicas anteriores, se logró combinar la oferta de trabajo sobrante en algunas regiones con la demanda insatisfecha en otras. En el caso de las migraciones con destino a Europa -Francia, Bélgica y Alemania sobre todo-los inmigrantes contribuyeron a satisfacer las necesidades laborales de aquellos países. Las corrientes internas tenían por destino ante todo los grandes centros urbanos industriales del país, localizados en 
la cornisa cantábrica, Cataluña, Levante y en torno a Madrid. Todo ello se inserta dentro de un abandono general del campo a favor de las ciudades, sobre todo las grandes ciudades, en todo el país. ${ }^{4}$

Estos procesos migratorios crearon fuertes flujos de dinero e inversiones. Desde Europa llegaron las remesas de los emigrantes que constituyeron una de las fuentes principales de divisas durante los años sesenta. Además, cuando cesó la presencia masiva de emigrantes españoles en Europa, éstos trajeron consigo sus ahorros que normalmente invirtieron en sus regiones de origen. Los españoles recién llegados a las ciudades mantuvieron sus vínculos con sus pueblos de origen; dichos vínculos tuvieron implicaciones económicas que se manifestaron en la compra de viviendas en las ciudades y en la rehabilitación de sus casas en sus pueblos de origen. De hecho, los vínculos entre los emigrantes y sus pueblos de origen contribuyeron a ralentizar lo que, al menos al principio, había parecido un proceso de declive rural irreversible.

Por otra parte, el capital humano acumulado en las zonas industriales fue esencial para el crecimiento económico del país. Hacía falta, tanto aquí como en Europa, mano de obra relativamente barata y con niveles medios de educación. Los españoles, al igual que los portugueses, italianos, griegos, turcos, marroquíes 0 argelinos, asumieron ese papel para la industria europea; los españoles procedentes del mundo rural hicieron otro tanto para las zonas de rápido crecimiento en España. El despegue económico español, al igual que el crecimiento de las economías europeas, hubiese sido imposible sin la activa participación de la fuerza de trabajo inmigrante.

Aparte del crecimiento económico en sí, esta corriente migratoria tuvo una importancia nada despreciable para la modernización de la sociedad española. Propició un reequilibrio de la población española a favor de las ciudades grandes y de sus entornos urbanos, creando por primera vez verdaderas conurbaciones en torno a Madrid, BarceIona y, en menor medida, Sevilla, Valencia y Bilbao (Reher 1994). El ritmo de crecimiento urbano alcanzó su cota más elevada de toda la historia española entre, aproximadamente, 1960 y 1975. Aunque a la altura de 1975 o 1980 España seguía contando con una población rural relativamente numerosa, la emigración de los años sesenta la había dejado bastante envejecida.

Es incuestionable que uno de los efectos derivados y no deseados de esta emigración fue el ocaso de muchas culturas tradicionales del mundo rural que fueron sacrificadas, a veces con bastante brutalidad, en aras de la modernización de la sociedad. A pesar de ello, sin embargo, el abandono del mundo rural también tuvo efectos positivos para el campo español. De entrada, facilitó el logro de mejores niveles de vida, tanto entre los que habían emigrado como entre los que permanecieron en los pueblos. Además, al aliviar la presión acumulada de población sobre los recursos económicos rurales, permitió una cierta concentración parcelaria de hecho para la población que

\footnotetext{
${ }^{4}$ En las zonas rurales de algunas provincias del interior del país, entre 1960 y 1970 se perdió más del 20 por cien de la población.
} 
permanecía en los pueblos, una concentración no lograda, salvo de forma imperfecta, por las políticas de concentración del régimen franquista. Ayudó, asimismo, a sentar las bases para una mayor especialización y mecanización de la producción agrícola que, pasados los años, iba a devolver a muchas zonas del campo español a una situación de relativa prosperidad económica y a la imperiosa necesidad de mano de obra, tan evidente en la actualidad en varias regiones del país.

Esta gran oleada migratoria terminó abruptamente a mediados de la década de 1970 a raíz básicamente de la crisis económica del petróleo. Una buena porción de los emigrantes españoles de Europa volvieron a España en parte por el cambio de coyuntura económica en el norte de Europa, en parte por un evidente cambio en las actitudes hacia los inmigrantes en esos países y, claro está, por los enormes cambios socioeconómicos y políticos que se habían producido en España. No deja de ser revelador que haya sido el propio proceso migratorio que ya tocaba su fin el que haya alimentado esos decisivos cambios. Paralelamente, también cesaron en buena medida las migraciones interiores, al menos las que se encauzaban hacia ciertas regiones y grandes ciudades. El resultado de todos esos cambios fue que el período 1975-1995 puede considerarse como un período de pocas migraciones. Las únicas migraciones de cierta envergadura durante este breve período fueron las llegadas relativamente tranquilas de extranjeros a España, muchos de ellos provenientes de países desarrollados que buscaban aquí un sitio donde jubilarse, así como la gran redistribución de la población dentro de las mismas conurbaciones. Lejos quedaban ya tanto el gran aluvión de personas que llegaba a las grandes urbes desde las zonas rurales del país o la irresistible atracción del extranjero que tanto había brillado en décadas anteriores.

En materia migratoria el período que transcurre entre 1975 y 1995 ha sido muy tranquilo en España. Todo ello iba a cambiar radicalmente a partir de mediados de los años noventa y sobre todo a partir de 1999-2000, cuando España se convirtió en uno de los principales destinos migratorios en Europa.

\section{EL PERÍODO RECIENTE DE EFERVESCENCIA MIGRATORIA}

En el plazo de unos pocos años España ha dejado de ser un país expulsor de (parte de) su propia población para convertirse en una potente fuente de atracción para inmigrantes provenientes de los países desarrollados, del norte de África, del continente americano, del este de Europa y de otras partes del mundo. ¿Qué ha convertido en tan corto plazo de tiempo a España en el país favorito de tantos inmigrantes? Esa evolución no es ajena al rápido crecimiento económico experimentado esos años, que ha multiplicado la capacidad de atracción del país como destino migratorio para auténticas masas de población procedentes de países obligados a soportar condiciones materiales de vida y niveles de bienestar social muy inferiores al nuestro. Y, sin pretender agotar las causas de un fenómeno necesariamente complejo, cabe mencionar también las realidades de 
una población española inmersa en un rápido proceso de envejecimiento y afectada ya por graves sesgos en su estructura por edad, los requerimientos - sectorial, espacial y temporalmente diferenciados- de unos mercados de trabajo heterogéneos y las generosas políticas de admisión migratoria que han venido practicando sucesivos gobiernos y diferentes administraciones. Al menos hasta el año 2008, todos esos factores han completado el cuadro de una sociedad muy atractiva para unos inmigrantes en busca de un destino para ellos mismos y sus familias mejor que el que razonablemente creían que les esperaba en sus sociedades de origen.

La llegada de población extranjera a nuestro país y la conversión de éste en claro receptor de inmigrantes se producen dentro de un proceso en el que cabe diferenciar, al menos, dos etapas o momentos clave. A tenor de los datos disponibles en las distintas estadísticas oficiales (gráfico 1$)^{5}$, puede apreciarse una primera fase, que corresponde con una etapa de entrada creciente de inmigrantes, cuyo flujo va aumentando de manera regular y sin grandes alteraciones. Esta primera etapa dura hasta finales de los años noventa. Así, en 1999, los nacidos en el extranjero - que, por tanto, eran de una u otra forma inmigrantes - constituían una fracción muy pequeña de la población total del país (alrededor del 1,9\%), lo que nos situaba como una de las naciones europeas con una baja tasa de inmigrantes, muy lejos de países de mucha mayor tradición inmigratoria como Alemania, Francia o el Reino Unido.

Diez años después, en 2009, la cifra de personas nacidas en el extranjero se acerca a los 6,5 millones, que conviven junto a 40,3 millones de nativos. La proporción de inmigrantes se ha elevado hasta casi el $14 \%$ de la población, consiguiéndose tal aumento en una segunda etapa, que cabe calificar de espectacular, ya que el crecimiento de la población inmigrante - en torno a 5 millones de individuos - se consigue en tan solo un período de diez años. Este ritmo de llegadas tuvo su punto culminante entre los años 2001 y 2004, aunque en términos absolutos las entradas en 2007 han sido las más numerosas ${ }^{6}$. Sea como fuere, el resultado es que las llegadas de inmigrantes dan cuenta del $77 \%$ del crecimiento de la población española en el periodo. Como resultado de todo ello, España no sólo ha contribuido decisivamente al crecimiento de la población inmigrante en Europa durante estos años, sino que ha pasado de ser uno de los países europeos con menor número de inmigrantes a convertirse en otro muy distinto, en el que éstos constituyen una fracción muy importante de su población.

La evolución de la inmigración, con la clara aceleración del fenómeno al inicio del siglo XXI, ha supuesto algunos cambios importantes respecto a las características que

\footnotetext{
${ }^{5}$ Es de sobra conocida la dificultad existente para hacer un cómputo certero del número de inmigrantes que residen en nuestro país. Junto a las ventajas e inconvenientes de las fuentes estadísticas disponibles (que pueden pecar por exceso o defecto) hay que considerar el efecto perturbador de la inmigración clandestina, cuya magnitud puede alterar las cifras que habitualmente se manejan sobre este fenómeno.

${ }^{6}$ Para los análisis anuales de las cifras es preciso prestar atención a los efectos que la depuración del Padrón Continuo, iniciada en 2005, puede tener sobre las cifras ofrecidas y las estimaciones en la evolución de los flujos (Domingo y Recaño 2007).
} 
Gráfico 1.

Evolución de la población extranjera (diversas fuentes) y porcentaje de extranjeros en la población total

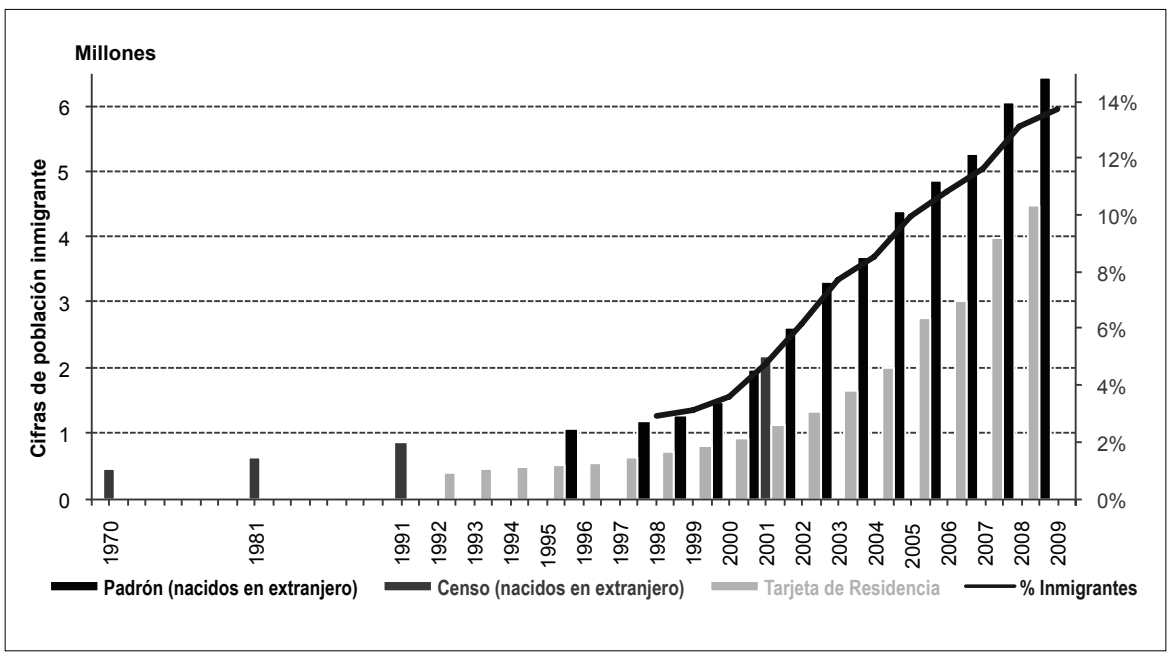

Fuente: INE: Censos y Padrón municipal de habitantes. Ministerio de Trabajo e Inmigración: Anuario Estadístico de Extranjería (1992 a 1997) y Boletines Estadísticos de Extranjería e Inmigración (de 1998 en adelante).

exhibe el colectivo de inmigrantes según la etapa del ciclo migratorio. Para dar cuenta de las principales características y de las transformaciones acontecidas basta con examinar algunos datos relevantes en ciertas fechas de referencia. Así, en lo que respecta a las nacionalidades predominantes de la población inmigrante en nuestro país (gráfico 2), puede apreciarse como en la etapa previa a la aceleración del ciclo migratorio predominaban los procedentes de países de la Unión Europea (42\%), seguidos de los africanos $(21 \%)$, y los procedentes de América del Sur (18\%). A finales de los noventa, la inmigración en España tenía un alto componente de trabajadores y jubilados europeos. En los años siguientes se empieza a hacer patente la presencia de personas de otros lugares que, por su distancia económica y, en algunos casos cultural, van a ir señalando con nitidez la brecha económica que convierte la migración en un fenómeno de masas hacia nuestro país.

En los primeros años del siglo XXI, al hilo del auge económico español y la pujanza de sectores como la construcción y los servicios, flujos crecientes de inmigrantes venidos fundamentalmente de América Latina (35\%) se incorporan a nuestro país, manteniéndose la presencia de europeos (31\%) y también de africanos (18\%). Respecto al 
Gráfico 2.

Evolución (\%) de la población inmigrante por grandes regiones de nacimiento

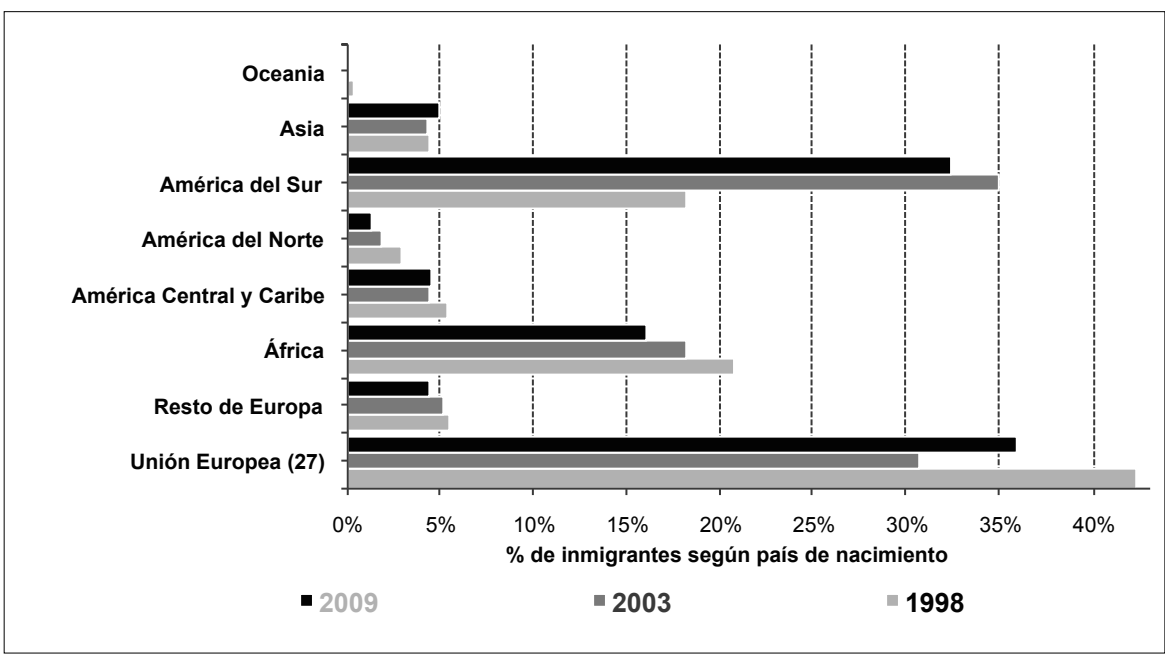

Fuente: INE: Padrón municipal de habitantes.

patrón de los años previos es de destacar el crecimiento importante de los procedentes de América Latina, que en esos años se sitúan a la cabeza respecto a la procedencia de los flujos (López de Lera 2006). Los últimos datos (2009) revelan algunos cambios en la distribución de los inmigrantes por origen. De nuevo, los venidos de la Unión Europea se sitúan a la cabeza (36\%), seguidos de los latinoamericanos (32\%) y de los venidos de África (16\%). Sin embargo, conviene aclarar que el incremento de los inmigrantes europeos se debe, fundamentalmente, al aluvión migratorio que en los últimos años han protagonizado las personas procedentes de algunos países de la Europa del Este que, también recientemente, se han incorporado como miembros de pleno derecho de la Unión Europea.

Un examen de la procedencia de la población inmigrante por países predominantes ayuda a concretar y a apreciar con mayor detalle los cambios acontecidos en este aspecto en los últimos años (gráfico 3). Una vez ordenadas por su peso relativo las principales procedencias, cabe apreciar como en 1998 la inmigración estaba encabezada principalmente por los oriundos de Marruecos, que encontraban en la agricultura, la construcción y los servicios sus principales nichos laborales (Requena y Cebolla 2009), seguida por trabajadores y jubilados europeos procedentes sobre todo de Francia, Alemania y Reino Unido. Entre los venidos de América Latina destacaban en esta fecha los argentinos. En 2003, coincidiendo con el incremento del flujo de inmigrantes hacia nuestro país, se aprecia claramente el incremento de las personas venidas del continente americano y en concreto de Ecuador y Colombia como principales orígenes 
(González y Echeverri 2009; Reher et al. 2009). Se consolida el flujo de inmigrantes argentinos, sobre todo como consecuencia de la grave crisis económica de aquel país en los años precedentes (Reher y Sánchez Alonso 2009).

Sin duda, pese a la importancia de la distancia física, las diferencias económicas, así como la cercanía cultural y lingüística han favorecido la llegada de personas del otro lado del Atlántico, sin desdeñar en absoluto el importante papel que en la dirección y cuantía de los flujos migratorios ejercen las redes sociales de los inmigrantes. Más cercanos

Gráfico 3.

Evolución (\%) de la población inmigrante por países de nacimiento predominantes

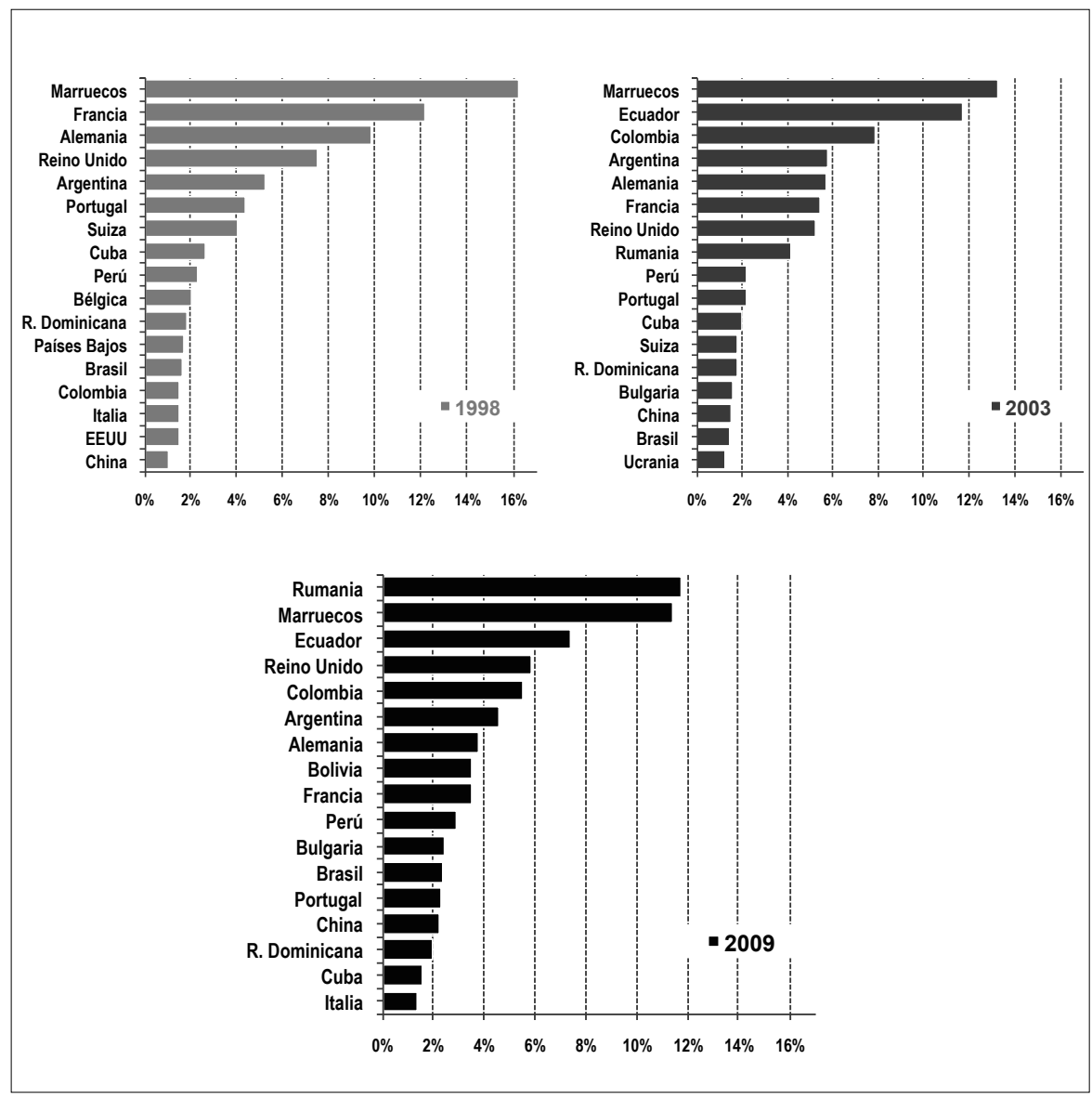

Fuente: INE: Padrón municipal de habitantes. 
geográficamente, aunque no en lo referente al idioma y la tradición cultural, siguen destacando los marroquíes en los puestos de cabeza, pero en las siguientes posiciones ya se aprecia el peso de los rumanos, cuyo contingente se aproxima al de otras naciones europeas como Reino Unido, Francia y Alemania. En el último año (2009), la situación muestra leves pero significativos cambios, como es la importancia que adquiere la población extranjera venida de Rumanía, que supera a los oriundos de Marruecos, al tiempo que se aprecia un descenso del peso relativo de ecuatorianos y colombianos, pese a que se mantienen como orígenes predominantes. Sin duda, la desestructuración social y económica de muchas de las economías de los países del este constituye la base de unos procesos de expulsión que encuentran elementos propicios para la atracción tanto en las distintas dinámicas económicas como en las peculiaridades institucionales y legales de países del sur de Europa como España (Finotelli 2007; Stanek 2009). El incremento notable de inmigrantes rumanos y, en menor medida, de búlgaros ejemplifica bien esos procesos.

Pasando de origen a destino, la localización espacial de la población inmigrante en nuestro país (gráfico 4) ha tenido, desde el inicio del proceso, una clara preferencia por determinadas regiones. Así, ambos archipiélagos (Baleares y Canarias), junto al Levante constituyen claros centros de recepción y absorción para la población foránea. Si bien en 1998 , el bajo número de inmigrantes daban a estas Comunidades pesos entre el $4 \%$ y el $7 \%$ de población extranjera, la situación va a cambiar de forma importante en la siguiente década. Así, a estas zonas de clara atracción, se añaden Madrid, Cataluña y Murcia, que incrementan de forma notable el peso de los venidos de fuera. También crecen, aunque en menor medida, Aragón, La Rioja, Navarra, Castilla-La Mancha, Galicia y Andalucía. Este aumento del peso de los inmigrantes coincide con la etapa de crecimiento de los flujos migratorios y algunas comunidades llegan a albergar entre el $8 \%$ y el $12 \%$ de población inmigrante en 2003 (salvo Baleares que ya entonces supera el 12\%). En 2009, Baleares Valencia y Madrid tienen más de un $18 \%$ de inmigrantes entre su población. Por su parte, Cataluña, Aragón, Canarias, La Rioja, Navarra y Murcia albergan más de un $12 \%$ y menos de un $18 \%$ de población inmigrante. El turismo, actividad predominante en algunas de estas regiones, y la construcción y los servicios, en buena medida también asociadas al turismo, constituyen, además de la agricultura, sectores que precisan mano de obra intensiva y su desarrollo a finales de los noventa y principios del siglo XXI han constituido un claro elemento de atracción para los trabajadores de otros países. Asi mismo, cabe considerar que el proceso de asentamiento configura una red social en el territorio que, progresivamente, favorece la acogida de nuevos grupos de inmigrantes en las mismas zonas, así como su extensión a zonas colindantes.

Un examen de las características del ciclo migratorio contemporáneo no puede completarse sin analizar otros rasgos demográficos básicos que caracterizan los flujos migratorios llegados a nuestro país desde mediados de los noventa hasta ahora. Uno de ellos es el que hace referencia a la composición por sexos de esta inmigración. Pese al tiempo transcurrido desde su enunciado y pese a los cambios acontecidos en muchos de los factores que pueden influir sobre las características de los movimientos migratorios, 


\section{Gráfico 4.}

\section{Población inmigrante en las Comunidades Autónomas \\ (\% de nacidos en el extranjero)}

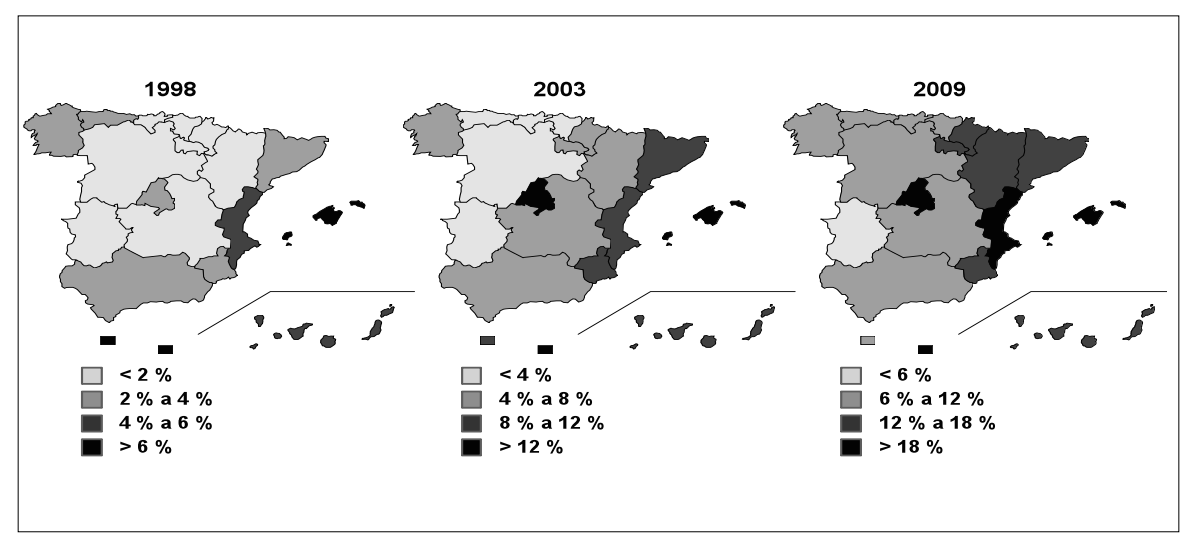

Fuente: INE: Padrón municipal de habitantes.

parece mantenerse, aunque solo con intensidad muy moderada, la máxima de Ravenstein acerca de la composición eminentemente masculina de los movimientos migratorios (Arango 1985). De acuerdo con el gráfico 5 , los flujos migratorios llegados a nuestro país en 1998 tenían una presencia muy similar de varones y de mujeres (prácticamente la mitad, el $49 \%$ de la población extranjera era de mujeres). Este equilibrio general escondía, sin embargo, diferencias importantes entre distintos colectivos. Así, los grupos de población extranjera claramente feminizados eran los llegados desde América del Sur (con un $64 \%$ de mujeres como promedio), mientras que en el otro lado de la escala, con una fuerte presencia masculina, estaban los venidos desde el continente africano (36\% de mujeres). La tradición cultural de los lugares de origen ha desempeñado, sin duda, un papel fundamental en esta dispar composición por sexos en unos y otros colectivos.

El aumento de los flujos migratorios a comienzos del siglo XXI ha supuesto una relativa masculinización del fenómeno. De hecho, los datos para el año 2003 sitúan en un $46 \%$ el peso de las mujeres dentro del total de población inmigrante - no nativaresidente en nuestro país. Todos los orígenes experimentan, en mayor o menor medida, un incremento en el peso del número de varones que acuden a nuestro país. Hay un proceso de masculinización destacable de 1998 a 2003 entre los africanos, pero lo es aún mayor entre los llegados de Asia y entre los venidos de América Latina y otros países del resto de Europa. Si bien entre los llegados de América siempre han predominado las mujeres, la reducción en su peso relativo favorece la masculinización del volumen general de la población extranjera. El incremento de estos flujos migratorios latinoamericanos, junto a procesos de reagrupación familiar, que en el caso de mujeres 
Gráfico 5.

Composición por sexos (\% de mujeres) de la población extranjera según grandes grupos de nacionalidad

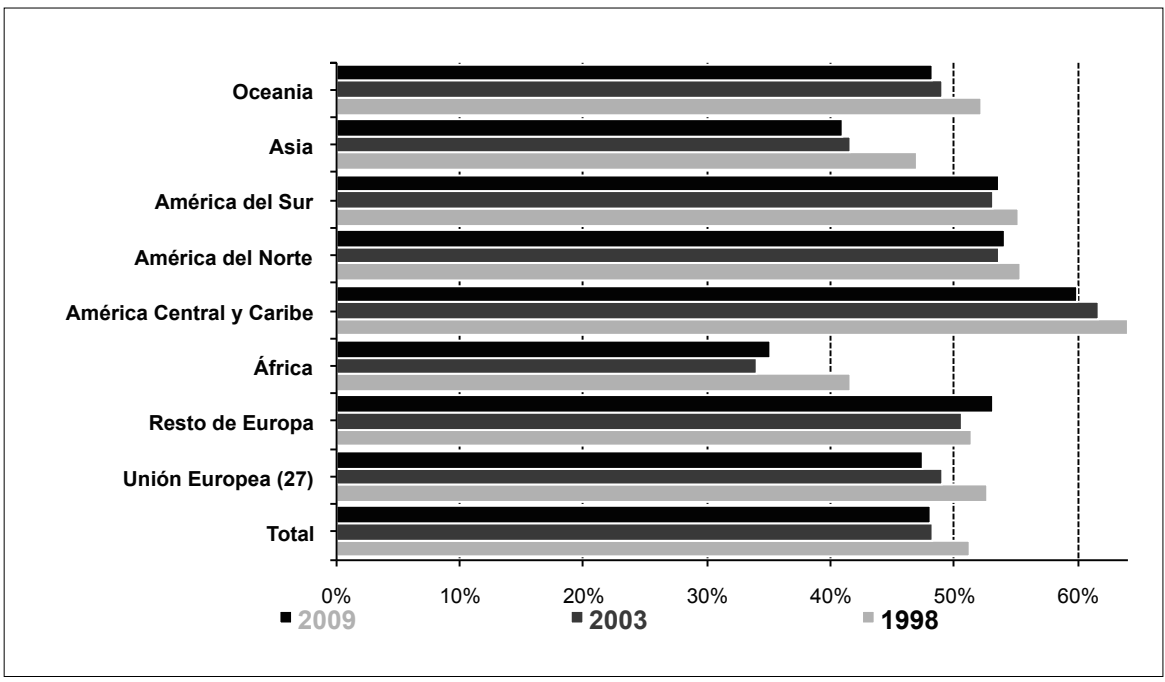

Fuente: INE: Padrón municipal de habitantes.

implica la llegada de sus parejas, debe haber influido en el descenso experimentado por las mujeres dentro de este colectivo de inmigrantes.

Los últimos datos (2009) no muestran grandes transformaciones sobre esta composición por sexos. De hecho se mantiene la relación entre los sexos con respecto a 2003, siendo entre los llegados de Asia, Unión Europea, América Central y Caribe y Oceanía donde se sigue dando una reducción de la presencia de mujeres, mientras que aumenta el peso de éstas entre los venidos del Resto de Europa, África y Norteamérica y América del Sur.

En cuanto a la composición por edad, el carácter eminentemente económico de los flujos migratorios recientes ha determinado que la mayor parte de los colectivos muestren una edad media joven-adulta, característica de aquellas personas que se encuentran en edad de trabajar. Tanto las curvas del porcentaje de cada colectivo de los inmigrantes por edad, así como la edad media (gráfico 6), dejan ver ese predominio de las edades típicamente activas, si bien cabe apreciar algunas diferencias notables según la procedencia y, también, con la evolución del fenómeno migratorio. Así, entre los inmigrantes de mayor edad figuran los venidos de la Unión Europea (sin Rumania), que tienen una aportación importante de personas en edad de trabajar, pero también en los grupos de edad más avanzados. De hecho, la edad media de este colectivo se aproxima a los 40 años, dado el peso de los mayores de 60 años entre sus componentes. Los más jóvenes 
son los oriundos de África y de América del Sur. Por otra parte, la intensificación de los flujos migratorios hacia España ha tenido un efecto rejuvenecedor entre la población. La afluencia de inmigrantes no solo ha sido más intensa, sino que además, han venido más jóvenes, dando lugar a un cambio en la composición por edad con el consiguiente descenso de la edad media y el incremento de población en los grupos de edad más claramente relacionados con la actividad laboral (Reher et al., 2008).

Gráfico 6.

Composición por edad (\%) y edad media de la población inmigrante según procedencia (2009)

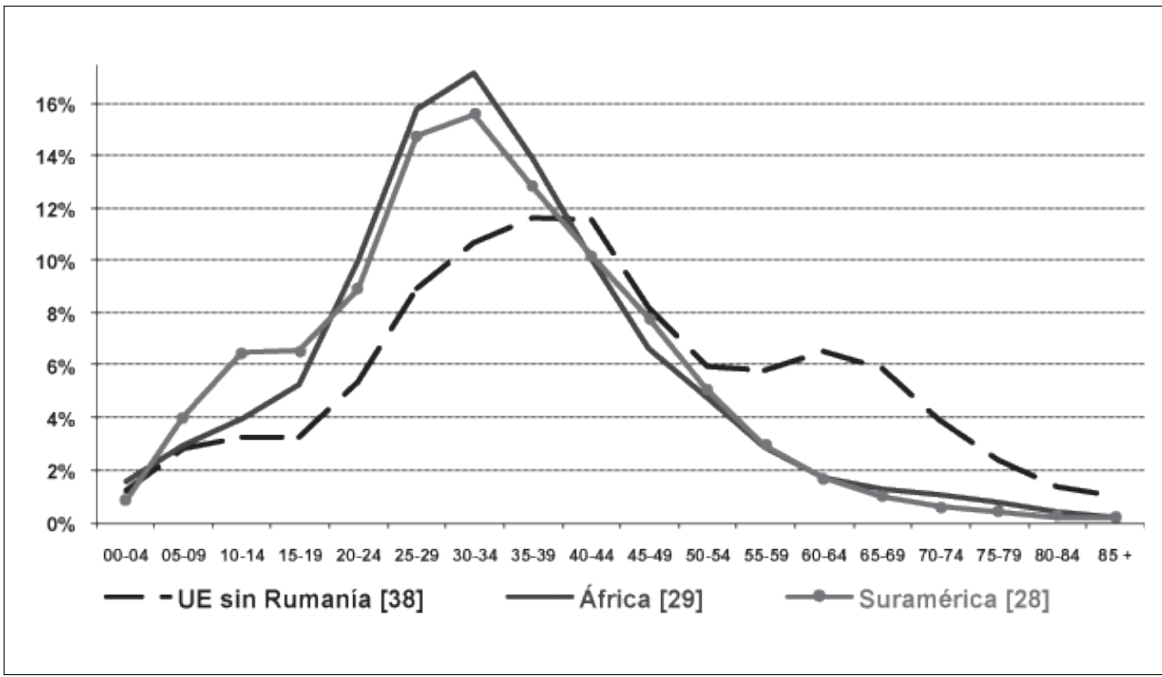

Nota: La edad media de cada colectivo figura entre corchetes en la leyenda.

Fuente: INE: Padrón municipal de habitantes.

Por último, dentro de este repaso a las principales características del reciente ciclo migratorio cabe dedicar un último punto de atención a los principales sectores de actividad económica que han recibido al grueso de esta población inmigrante (gráfico 7). Como puede apreciarse, la mano de obra inmigrante se ha dirigido fundamentalmente hacia el sector dedicado a los servicios, que acoge a más del $60 \%$ de esta población. Le siguen en importancia el sector de la construcción, la industria y, en último lugar, la agricultura. La evolución del ciclo migratorio ha coincidido con cambios importantes ligados al desarrollo económico y con la preponderancia que en los años iniciales del siglo XXI han adquirido, junto a los servicios, otros sectores económicos como la construcción. De 
Gráfico 7.

Distribución (\%) de la población extranjera por sectores económicos

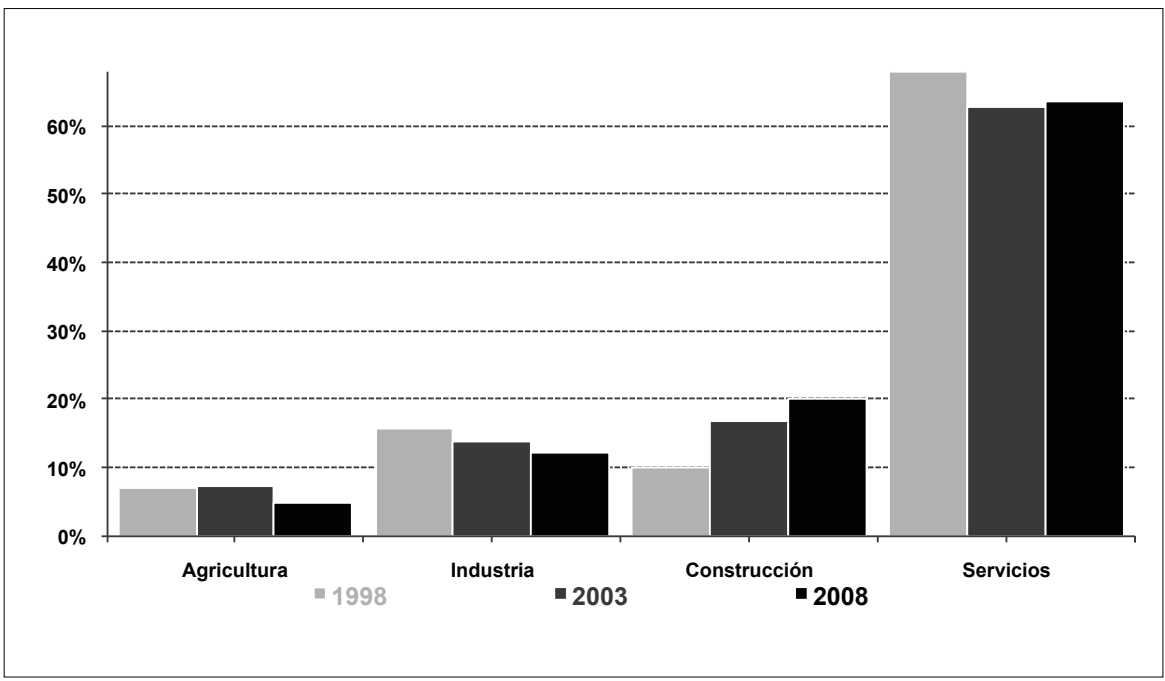

Fuente: INE: Encuesta de Población Activa, segundos trimestres.

hecho, la observación de los cambios acontecidos en los tres momentos analizados deja ver cómo la intensificación de los flujos migratorios coincide con una disminución de la población inmigrante dedicada a los sectores de agricultura, industria y servicios y una incorporación importante y en aumento, al menos hasta 2008, al sector de la construcción. Sin duda, la crisis económica ha venido a operar un importante cambio sobre esta situación, dando lugar a una profunda alteración de la situación de los inmigrantes en nuestro país y en la misma dinámica migratoria existente hasta el momento.

\section{CRISIS ECONÓMICA Y CAMBIO DE CICLO MIGRATORIO}

En el momento presente parece muy extendida entre los expertos la idea de que el ciclo inmigratorio expansivo de la sociedad española se puede ya dar por agotado (Aja, Arango y Oliver 2008; Aja, Arango y Oliver 2009; Requena y Reher 2009). Uno de nuestros más destacados especialistas en la materia resume esta tesis con meridiana claridad cuando afirma que "la década prodigiosa de la inmigración en España ha terminado" (Arango 2009: 54). Destacados responsables políticos nos trasmiten también la misma 0 parecida opinión cuando declaran que los españoles hemos cerrado un ciclo importante 
en nuestro modelo inmigratorio ${ }^{7}$. Lo que esto significa es que tras casi un decenio de crecimiento expansivo de la inmigración, durante el cual España se ha convertido en el primer receptor de inmigrantes de la Unión Europea y en uno de los primeros del mundo, la afluencia migratoria a nuestro país ha comenzado a desfallecer, si es que no se ha paralizado por completo. El cambio de ciclo migratorio, de estar produciéndose realmente, implicaría dos importantes consecuencias: primera, que nuestro país absorbería en los próximos años cantidades de inmigrantes mucho menores que las que fue capaz de recibir en el decenio 1998-2008; y segunda, que el retorno de los inmigrantes a sus países de origen aumentaría en comparación con lo sucedido los últimos años. En otras palabras, con el cambio de ciclo los saldos migratorios se reducirán de forma importante y, eventualmente, se detendrán por completo.

¿En qué se sustenta la idea de que el ciclo migratorio expansivo se ha agotado en España? En primer y más destacado lugar, en las cifras disponibles ${ }^{8}$ sobre los flujos migratorios, que apuntan a un ritmo decreciente en términos absolutos de la afluencia inmigratoria durante estos últimos años. Si se admite esta idea del cambio de ciclo, 2007 habría sido el año en el que el saldo migratorio habría alcanzado su pico máximo en nuestro país: ese año el número neto de empadronamientos de inmigrantes ascendió a 795 mil (véase el gráfico 8). Frente a éstos, los nuevos empadronamientos registrados en 2008 (373,5 mil) representan un incremento del número de inmigrantes de sólo el 6,2\% respecto al año previo, el más bajo de los últimos años; suponen, también, un descenso del saldo migratorio absoluto de en torno al cincuenta por ciento respecto al que se produjo en 2007. A la espera de conocer los datos del padrón municipal correspondientes a enero de 2010, que podrían reflejar un saldo neto aproximadamente nulo para las entradas (altas) y salidas (bajas) de inmigrantes durante el año 2009, hay que señalar que diversos colectivos ya han dado muestras en los últimos años de estar experimentando una tendencia a la contracción de sus flujos de entrada. Tal ha sido el caso de ecuatorianos, argentinos y colombianos, ampliamente contrarrestado, eso sí, por la intensa afluencia de rumanos hasta 2007. No obstante, en términos relativos, el descenso de entradas en 2008 ha sido especialmente acusado entre rumanos y argentinos.

\footnotetext{
${ }^{7}$ Véase, por ejemplo, la intervención de este tenor de la Secretaria de Estado de Inmigración en el Foro de la Nueva Sociedad que tuvo lugar en Madrid en el pasado mes de noviembre de 2009.

${ }^{8}$ En este trabajo recurrimos a los datos del Padrón Municipal Continuo para analizar los flujos migratorios. Como se sabe, pese a sus problemas, el Padrón Municipal Continuo es la fuente canónica para medir la intensidad de los flujos migratorios en nuestro país. Obviamente, los saldos anuales se computan como la diferencia entre la población empadronada en dos años sucesivos. Arango (2009) hace uso también de otras fuentes, además del padrón, para llegar a parecidas conclusiones.
} 
Gráfico 8.

Crecimiento anual del número de inmigrantes en España (1997-2008).

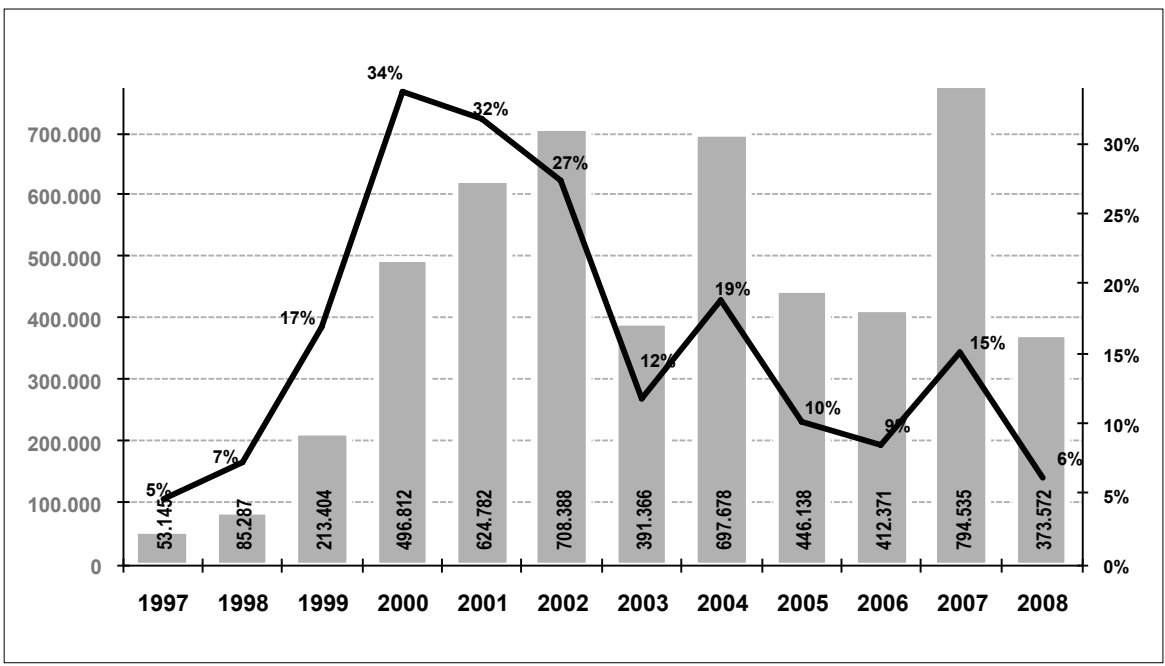

Fuente: Padrón Municipal de Habitantes, INE. El dato de 1998 se ha obtenido por interpolación.

Junto a estos datos, que juzgamos por sí mismos muy reveladores del cambio de ciclo migratorio, conviene tener en cuenta la serie de las tasas anuales de crecimiento del número de inmigrantes, que nos presentan un panorama muy elocuente del curso que ha seguido la inmigración en España en estos últimos años (véase, de nuevo, el gráfico 8). En términos relativos, las entradas de inmigrantes en nuestro país han seguido un curso descendente desde el año 2000, el momento de su mayor crecimiento. Desde este punto de vista, el ciclo inmigratorio de finales del siglo XX y principios del XXI se habría iniciado hacia (finales) de los años noventa y se habría expandido hasta el año 2000, momento a partir del cual habría comenzado a desacelerarse. En los ocho años posteriores a 2000 la tendencia descendente sólo se habría interrumpido en 2004 y 2007. Si los datos padronales terminan reflejando, como parece que efectivamente harán ${ }^{9}$, un crecimiento aproximadamente nulo de la inmigración en 2009, las razones para defender el agotamiento del reciente ciclo migratorio español ganarán un peso decisivo.

${ }^{9} \mathrm{Al}$ menos, eso es lo que parece sugerir lo que ha sucedido durante los primeros meses del año, durante los cuales las entradas de inmigrantes compensan las salidas de España. En todo caso, conviene tener en cuenta a efectos del cómputo de las salidas el posible desfase entre la desaparición real del inmigrante de su lugar de residencia y su baja en el Padrón. 
Como no podía ser de otro modo, estos datos sobre el cambio de los saldos migratorios son precisamente los que cabría esperar del entorno económico en que se han producido. Más arriba hemos visto que uno de los factores que con más fuerza ha atraído hacia España los grandes flujos migratorios llegados durante el boom ha sido el crecimiento económico intenso y sostenido que ha experimentado el país. Nada de particular tiene, por tanto, que cuando se produce un deterioro en las circunstancias económicas -tanto más si es de la magnitud y la intensidad del que ha acaecido en España-el país pierda atractivo para los potenciales inmigrantes.

Por lo tanto, además de las evidencias empíricas sobre el número de empadronamientos, el argumento fundamental en que se apoya la tesis del cambio de ciclo migratorio es, desde luego, de índole económica: una vez que han desaparecido las condiciones económicas que han facilitado la entrada masiva de inmigrantes en nuestro país, es de esperar que los flujos desciendan de forma apreciable o incluso se lleguen a interrumpir en los próximos años. Es obvio a estas alturas que el dinamismo económico del país receptor no es el único factor que atrae población foránea, pero sin él difícilmente se puede esperar que se produzcan entradas masivas de inmigrantes. Y los hechos a este respecto son bien conocidos: tras quince años de crecimiento económico sostenido, la sociedad española -inmersa de lleno en un contexto económico internacional recesivo de dimensiones desconocidas en las últimas décadas - comienza a dar serias muestras de decaimiento en el año 2007. En el segundo trimestre de 2008 se experimenta un crecimiento nulo del PIB; desde entonces y hasta el momento presente, las tasas de crecimiento del PIB de los seis trimestres siguientes, es decir, los dos últimos de 2008 y los cuatro de 2009, han sido negativas.

Uno de los mecanismos fundamentales por los que el crecimiento económico se convierte en elemento de atracción de inmigrantes es la generación de una creciente oferta de puestos de trabajo potencialmente atractivos para ellos. Y, a la inversa, cuando el crecimiento económico se ralentiza o se hace negativo, dejan de ofrecerse nuevos puestos de trabajo o se destruyen los ya existentes; entonces, el fenómeno del desempleo crece, las dificultades para permanecer integrado en el mercado de trabajo aumentan y gran parte de las condiciones materiales que durante la fase alcista del ciclo económico hacían atractivo al país para los inmigrantes desaparecen. La afluencia de nuevos inmigrantes se ralentiza o se detiene e incluso cabe esperar que muchos de los ya establecidos se vean más o menos forzados a abandonar el país. El funcionamiento de este mecanismo es claro para los inmigrantes llamados económicos, que resultan ser una gran mayoría de los que han llegado a España en el último decenio (Requena y Reher 2009). Sin embargo, es igualmente claro que las coyunturas económicas adversas pueden llegar a inhibir también los movimientos de otros tipos de migrantes potenciales (como jubilados 0 altos profesionales), sobre todo en la medida en que no son exclusivas de un único país sino que afectan a los posibles emisores de esos otros inmigrantes.

En España, en el periodo que media entre principios de 2007 y finales de 2009, el fenómeno del desempleo entre los inmigrantes se ha disparado al punto de que la tasa de paro de la población inmigrante excede en más de diez puntos a la de la población 
autóctona (28,3\% frente a $16,7 \%$ en el cuarto trimestre de 2009 según datos de la EPA). De hecho, durante el bienio 2007-2009 el desempleo inmigrante ha generado alrededor de la tercera parte $(31,4 \%)$ del desempleo total del país, dato que hay que poner en perspectiva teniendo en cuenta que a comienzos de ese bienio los inmigrantes representaban sólo el $16 \%$ de la fuerza de trabajo en España. Dicho en otros términos, si en el cuarto trimestre de 2009 había 0,2 inmigrantes ocupados (3,091 millones) por cada español nativo con empleo (15,392 millones), había también 0,4 inmigrantes parados (1,221 millones) por cada nativo en la misma situación (3,097 millones). Finalmente, si los inmigrantes representaban en ese cuarto trimestre de 2009 el 17,5\% de la población potencialmente activa (16-64 años) con residencia en España, daban cuenta del 28\% del fenómeno total del paro.

Este rápido e intenso aumento del desempleo entre los inmigrantes ${ }^{10}$ ha venido propiciado inicialmente no tanto por la destrucción de puestos de trabajo como por el aumento de la población activa; sólo desde finales del año 2008 la destrucción de empleo da cuenta del aumento del paro entre los inmigrantes (Oliver 2009). Que la población activa inmigrante (demanda potencial de empleo) haya seguido creciendo cuando la oferta real de puestos de trabajo ya había comenzado a disminuir significa que el ajuste entre ambas magnitudes no ha sido automático ni instantáneo; más bien —como suele suceder en estas coyunturas - se han debido producir desfases temporales que responden a varios factores, desde la falta de información actualizada a la composición sectorial de la fuerza de trabajo o la mayor propensión a buscar empleo de inmigrantes que llegaron en movimientos que inicialmente eran de reagrupación familiar (Oliver 2009). Ahora bien, a los efectos de analizar el cambio de ciclo migratorio es también interesante centrar la atención en la evolución de la oferta de empleo a los inmigrantes que realmente se ha producido en el país que en el desempleo. El gráfico 9 representa la evolución del número absoluto de empleos ocupados por inmigrantes (en el eje de la izquierda) y nativos (en el eje de la derecha) en España durante el boom inmigratorio, desde 1997 hasta el cuarto trimestre de 2009.

Los datos (recogidos por la Encuesta de Población Activa) muestran el proceso de fuerte creación de empleo durante estos años, que se prolonga hasta el tercer trimestre de 2007 en el caso de los nativos y hasta el segundo trimestre de 2008 en el caso de los inmigrantes. Entre los nativos españoles el empleo creció un 34\%, desde los 12,7 millones hasta los 17; entre los inmigrantes, el crecimiento fue de un impresionante $856 \%$, desde los 0,36 millones de 1997 hasta los 3,48 millones del segundo trimestre de 2008. Desde el año 2007 el impacto de la crisis económica comienza a hacer mella en el mercado de trabajo español. El máximo registro histórico de puestos de trabajo en España (20,5 millones de ocupados) se alcanza en otoño de 2007, momento a partir del cual comienza la destrucción de empleo. En los dos años siguientes se destruyen 1,8 millo-

\footnotetext{
${ }^{10}$ Es sabido que incluso en los momentos de gran crecimiento económico el desempleo entre los inmigrantes ha sido mayor que entre los nativos en España.
} 
Gráfico 9.

Evolución del empleo en España.

Nativos e inmigrantes, números absolutos en millones

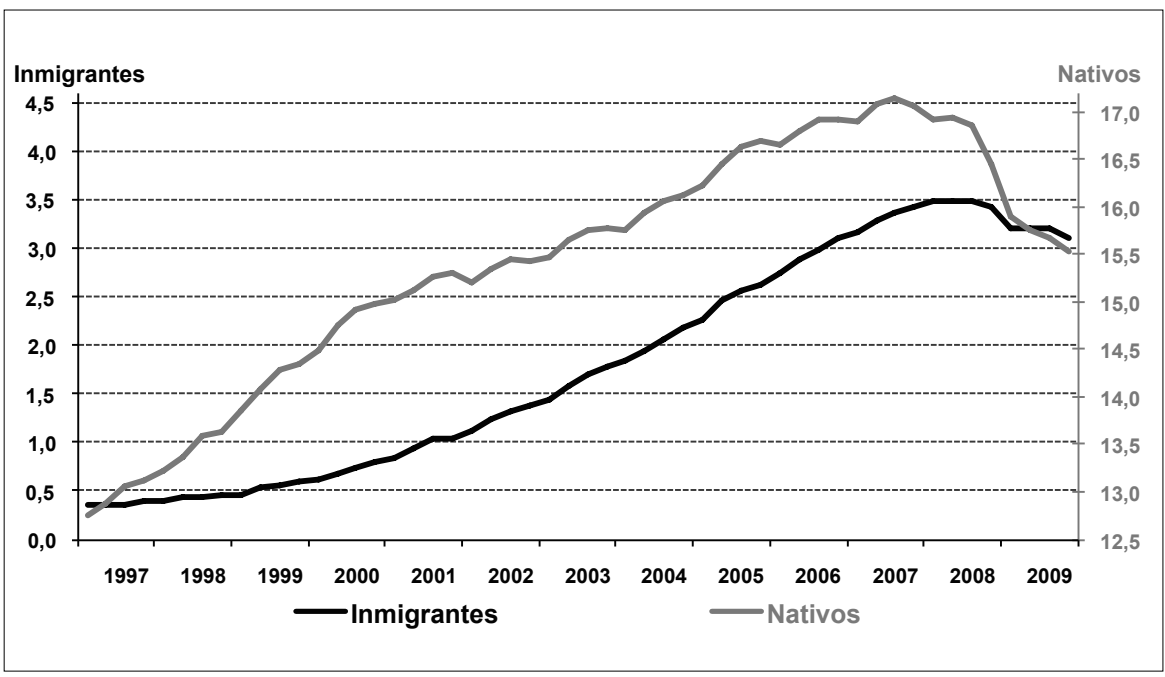

Fuente: Encuesta de Población Activa, INE.

nes de puestos de trabajo, un $9 \%$ de los empleos existentes. Los nativos pierden 1,6 millones de empleos entre el tercer trimestre de 2007 y el cuarto de 2009; los inmigrantes pierden 380 mil empleos entre el segundo trimestre de 2008 y el cuarto (trimestre) de 2009. En términos relativos (gráfico 10), esa destrucción de empleo desde el máximo alcanzado ha sido ligeramente superior para los inmigrantes (11\%) que para los nativos (9\%).

Con una perspectiva más amplia, en el gráfico 11 se representa la evolución del crecimiento relativo del empleo de los inmigrantes en términos intertrimestrales y anuales para el periodo 1997-2009. Aquí no nos detendremos en las oscilaciones trimestrales, en las que en todo caso destacan los fuertes aumentos de los segundos trimestres de los años 1999, 2001 y 2002 y la intensa destrucción a comienzos de 2009. Lo realmente interesante a nuestros fines son los datos estilizados del cambio anual, que dibujan un panorama de tasas de crecimiento anual en aumento hasta el segundo trimestre del año 2001, momento en que se alcanza la tasa de crecimiento anual máxima del periodo (39,3\%); desde entonces las tasas, aunque positivas, experimentan una evolución descendente hasta el último trimestre de 2008 , en el que el empleo de los inmigrantes prácticamente no crece en términos anuales. En el año 2009 las tasas anuales de los cuatro trimestres son ya negativas.

El ciclo de crecimiento del empleo inmigrante es, así, muy similar al del crecimiento de los stocks de inmigrantes que se representó en la curva del gráfico 8: subida brusca hasta el entorno de los años 2000 y 2001; después, lenta caída de unas tasas positivas hasta finales de 2008; y finalmente, probable crecimiento nulo en el año 2009. Por 
Gráfico 10.

Evolución del empleo en España. Nativos e inmigrantes, números relativos (Nativos 3T/2007=100; Inmigrantes 2T/2008=100).

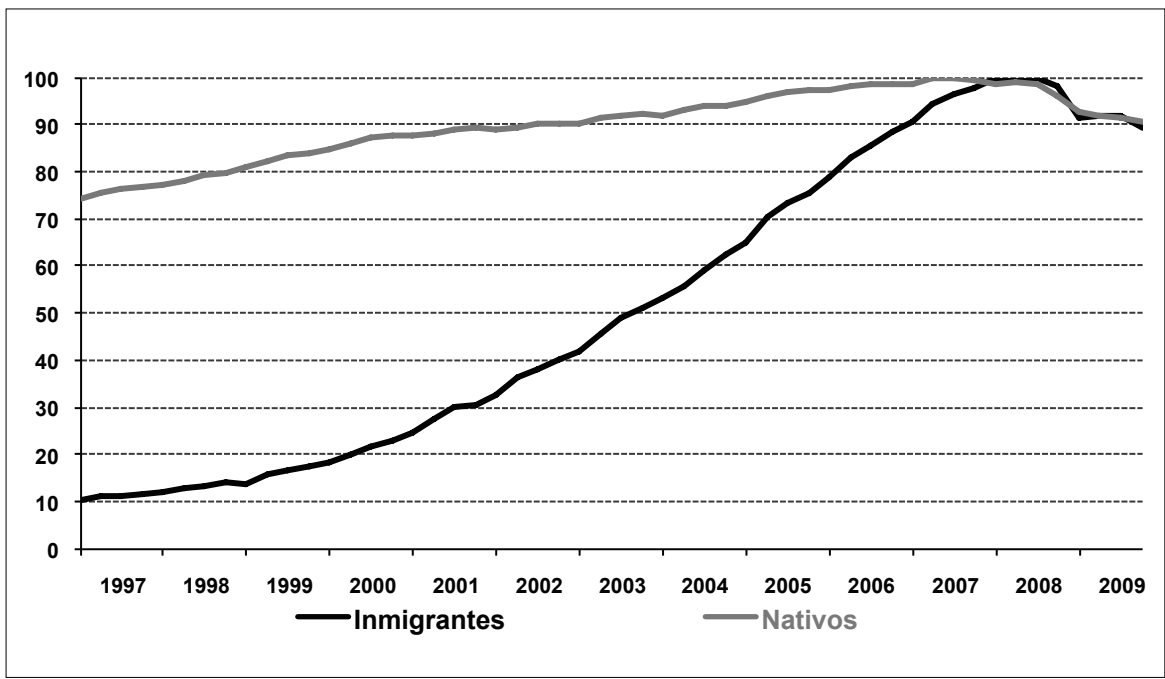

Fuente: Encuesta de Población Activa, INE.

Gráfico 11.

Crecimiento del empleo de los inmigrantes en España.

Variación intertrimestral y anual en tanto por ciento .

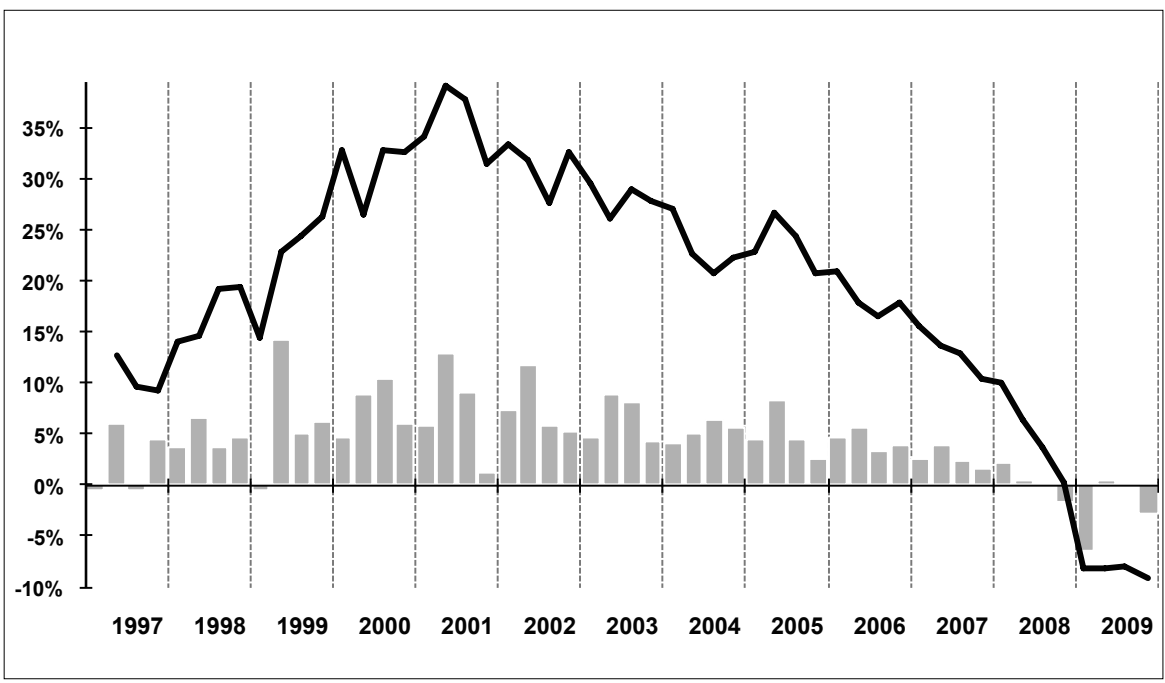

Fuente: Encuesta de Población Activa, INE. 
lo tanto, considerando el cambio a lo largo del tiempo, la correspondencia entre las tasas de cambio de la población inmigrante y sus empleos, aunque imperfecta, revela un notable paralelismo en las trayectorias de sus magnitudes que sugiere dos cosas. Primera, en España la oferta de puestos de trabajo adecuados a las condiciones de los inmigrantes ha sido, como mínimo, una condición necesaria de la explosión migratoria. La estrecha vinculación de la numerosa oferta de empleos generados por la economía española a la voluminosa llegada de inmigrantes es la que cabe esperar de una inmigración de naturaleza eminentemente económica. Segunda, esa correspondencia entre la cantidad de población inmigrante y su volumen de empleos nos lleva a pensar en un agotamiento del ciclo migratorio debido al cese en la generación de nuevos puestos de trabajo y la destrucción de empleos asociadas a la recesión económica.

Creemos, en suma, que la recesión económica de final de la primera década del nuevo siglo está suponiendo el fin de la fase alcista del boom migratorio español de comienzos del siglo XXI en la medida en que ya no se puede esperar que la creación de nuevos puestos de trabajo siga atrayendo a masas numéricamente importantes de inmigrantes.

\section{EL FUTURO dE LAS MIGRACIONES INTERNACIONALES EN ESPAÑA: UN ENSAYO dE PREVISIÓN}

Una vez agotado el atractivo económico del país con la drástica caída de la oferta de puestos de trabajo apropiados para dar empleo a los inmigrantes, ¿qué futuro le aguarda a la inmigración en España? Cualquier ensayo de prognosis a este respecto es muy arriesgado por varias razones. En primer lugar, los movimientos migratorios responden a una causalidad múltiple que, además, opera de forma simultánea como mínimo en las sociedades de origen y en las de destino. En segundo lugar, el ejercicio de previsión se debe basar en los valores pronosticados de diferentes factores, lo que necesariamente multiplica la incertidumbre de los resultados. Ello hace difícil, en tercer lugar, elaborar modelos teóricos capaces de controlar las diferentes variables que inciden en las decisiones migratorias y que configuran los contextos más propicios para desencadenar los movimientos. Por si todo ello no bastara, en cuarto lugar, tratar de contrastar y aplicar los modelos supone contar con datos observados y previstos de los que no siempre o raramente se dispone. No obstante lo anterior, en este último epígrafe vamos a arriesgar un pronóstico sobre el futuro de la inmigración en la España de los próximos años que, pese a todas las cautelas que se deben adoptar en estos casos, juzgamos razonablemente fundado. Con él no pretendemos anticipar el futuro en todos sus detalles, sino más bien bosquejar el contexto previsible en el que pueden discurrir los flujos migratorios en los años venideros. Aquí no presentamos un modelo formalizado de previsión de la inmigración ${ }^{11}$, sino que nos limitamos a desarrollar verbalmente nuestro argumento.

\footnotetext{
${ }^{11}$ Por su parte, Alloza, Ángel y Vázquez (2009) estiman un modelo econométrico de previsión de los futu-
} 
Como hemos visto, el crecimiento económico y la correspondiente oferta de puestos de trabajo en el país de destino son un factor primordial de los movimientos migratorios cuyo peso se ha agotado por el momento en España. Como acabamos de ver, durante el año 2009 el producto interior bruto español ha decrecido un 3,1\%; el empleo de los inmigrantes se ha reducido un $9 \%$. Esos datos, considerados junto a la evolución reciente de las tasas de crecimiento de la población y el empleo inmigrantes, nos han llevado a insistir en el agotamiento del reciente boom español, es decir, en el fin de la fase expansiva del ciclo migratorio y el comienzo de un declive inmigratorio. Lo que significa, en otros términos, que como poco hasta que el país no recupere la senda del crecimiento económico y sea capaz de generar empleo a un ritmo apreciable, no deberíamos esperar que se vuelvan a producir flujos de parecida intensidad a los vividos en el último decenio.

Cosa distinta es que en ese panorama general de nula o escasa generación de empleo se abran oportunidades laborales para colectivos específicos de inmigrantes como consecuencia de cambios sectoriales en la sociedad española, de un desarrollo especializado de la economía o de la aparición de nuevas necesidades sociales. Por ejemplo, sabemos que la evolución de la población femenina española, con su progresiva cualificación educativa y profesional y su creciente participación en el mercado de trabajo, ha generado una importante demanda de puestos de trabajo en el sector de los servicios a los hogares - trabajo doméstico, cuidado de niños y de ancianos-especialmente atractiva por varias de sus características para los inmigrantes. No es descabellado pensar que en el futuro, y a diferencia de lo que seguramente sucederá con otro tipo de actividades económicas en otros sectores como la construcción, la demanda de trabajo en servicios domésticos se mantendrá e incluso se incrementará. De cumplirse esta previsión, cabría esperar una mayor femenización en la inmigración a España. Pero huelga decir que hacer pronósticos particularizados en este último sentido es sumamente arriesgado.

En todo caso, y de acuerdo con el saber acumulado (Hirschman, Kasinitz y de Wind 1999; Massey et al. 2002), los factores estrictamente económicos en la sociedad de destino, con ser primordiales, no son los únicos que se deben considerar a la hora de evaluar su potencial inmigratorio. Entre los elementos de atracción que suelen distinguir los modelos teóricos al uso para explicar las migraciones internacionales hay también que tener en cuenta factores demográficos y, en particular, los sesgos estructurales de la población en la sociedad de acogida. Aquí nos referimos, ante todo, a los desajustes en la estructura por edades de la población que pueden suponer un déficit de fuerza de trabajo y plantear necesidades laborales que podrían cubrirse con población foránea. Cabría también considerar aquí otros posibles desajustes, más específicos, relacionados con el stock de capital humano existente en el país de destino y su eventual déficit de,

ros stocks y flujos de inmigrantes con horizonte en el año 2014 basado, fundamentalmente, en las diferencias en las condiciones macroeconómicas de los países de origen con España. Sus conclusiones apuntan a una disminución continuada de los flujos inmigratorios con destino en España. 
por ejemplo, determinados niveles de formación, que podrían atraer inmigración. Pero, de momento, nos ceñiremos a la futura estructura de edades de la población española. Según las proyecciones del Instituto Nacional de Estadística (INE), la población residente en España potencialmente activa (16-64 años) disminuirá en España entre 2009 y 2019 en aproximadamente 0,754 millones de personas $(-2,4 \%)$. Ahora bien, dicha disminución es el resultado agregado de un aumento de 2,140 millones de personas (+19\%) entre los 45 y los 64 años y dos decrementos: uno de 0,5 millones de personas entre los 16 y los 24 años $(-9,9 \%)$ y otro, de mucha más consideración, de 2,445 millones de personas entre los 25 y los 44 años (-16\%). ${ }^{12}$ En nuestro país este último tramo de edades (25-44 años) ha sido particularmente relevante a efectos migratorios, pues el grueso de los inmigrantes económicos llegados a España entre 1997 y 2007 se ha concentrado precisamente en esas edades de máxima actividad laboral. ${ }^{13}$ Hay que tener en cuenta que esas proyecciones del INE ya incorporan un saldo migratorio agregado positivo a lo largo del periodo de 0,445 millones de inmigrantes: unos flujos ligeramente positivos pero decrecientes de inmigrantes hasta el año 2012 y una leve recuperación posterior hasta 2018. Eso significa que si la economía española fuera capaz de crecer a un ritmo suficiente como para generar más puestos de trabajo podría encontrarse con una fuerza laboral, en especial de jóvenes adultos, potencialmente insuficiente para cubrir la oferta de empleos. Es decir, si se dieran todas esas circunstancias, la inmigración podría ser un recurso al que volver a acudir para paliar la insuficiente oferta de mano de obra autóctona, como ya se hizo durante el pasado boom migratorio.

En este capitulo de los factores que atraen a los inmigrantes merecen una especial atención, por otra parte, las políticas migratorias en destino que tienen por objeto la integración, incluyendo de manera destacada en nuestro país la provisión de servicios públicos y bienestar social. Parece que en efecto hay un cierto acuerdo en considerar que en España los factores propiamente institucionales han favorecido la llegada de inmigrantes a una sociedad que ya de por sí era muy atractiva desde el punto de vista económico y laboral. El caso español se ha caracterizado, como es sabido, por sus generosas políticas de admisión migratoria, por las repetidas regularizaciones de inmigrantes indocumentados y por un reconocimiento munífico -muy amplio e independiente del estatus legal- de derechos sociales a los inmigrantes. Por ello, junto a los factores económicos, las facilidades de entrada al país y el acceso universal a servicios públicos de bienestar social como la sanidad o la educación han constituido un impulso decisivo de la reciente experiencia inmigratoria española. De cara al futuro,

\footnotetext{
${ }^{12}$ Como es sabido, estos decrementos en la población de jóvenes y jóvenes adultos se va a producir como consecuencia del continuado déficit de natalidad que ha venido acumulando nuestro país desde mediados de los años setenta.

${ }^{13}$ Por ejemplo, según los datos del Padrón Municipal, en el año 2007 la población inmigrante (nacidos en el extranjero) de entre 25 y 44 años constituía el $51,3 \%$ del conjunto de los nacidos fuera de España de todas las edades; los nacidos en España de las mismas edades representaban sólo el $31 \%$ del conjunto de los nativos.
} 
es posible que dichos elementos institucionales puedan seguir operando como hasta ahora, es decir, favoreciendo la llegada de inmigrantes. Pues si bien es cierto que la nueva legislación en materia de extranjería a menudo se ha presentado en los medios de comunicación como un intento de limitar la reunificación familiar y restringir los permisos de trabajo para contener la afluencia de nuevos inmigrantes, nosotros pensamos sin embargo que, en términos generales y por si sola, la reciente ley no va a alterar sustancialmente las condiciones de acceso y estancia en el país. ${ }^{14}$ Ahora bien, incluso así es difícil saber hasta qué punto esas condiciones institucionales por lo general muy amistosas con el inmigrante continuarán constituyendo un incentivo para desplazarse a España en ausencia de una oferta amplia y dinámica de empleo.

Sea como fuere, es claro que las condiciones institucionales desempeñan por fuerza un papel destacado como posible elemento de motivación de la reagrupación familiar de los inmigrantes, otro de los factores no estrictamente económicos que hay que tener en cuenta en la previsión de los flujos migratorios de los años venideros. En el caso español, el reconocimiento de los derechos a la educación ${ }^{15}$, al acceso al sistema de la Seguridad Social y a la asistencia sanitaria en las mismas condiciones que los españoles seguramente ha sido en muchos casos un acicate importante para promover la reagrupación de los familiares que se quedaron en el país de origen. La nueva ley consagra como derecho la reagrupación de, básicamente, la familia nuclear: el cónyuge o pareja de hecho, los hijos menores de 18 años y los ascendientes en primer grado mayores de sesenta y cinco años (o cuando concurran razones humanitarias).

El contexto institucional favorable a la reunificación familiar puede entonces convertirse en un factor de atracción de nuevos inmigrantes impulsados por la intención de sus predecesores de reconstruir las unidades familiares rotas por la migración. Por lo que sabemos, en torno a la cuarta parte de los hijos de los inmigrantes en España residían en 2007 en sus países de origen (Reher et alii. 2008), lo que, sumado a los padres y cónyuges en la misma situación, ofrece, al menos en teoría, un amplio margen de oportunidades para llevar a la práctica estos movimientos de reagrupación familiar. Las experiencias de otros países con más tradición migratoria que el nuestro muestran que

\footnotetext{
${ }^{14}$ Ley Orgánica 2/2009, de 11 de diciembre, de reforma de la Ley Orgánica 4/2000, de 11 de enero, sobre derechos y libertades de los extranjeros en España y su integración social. Básicamente, la ley alarga la estancia máxima en los centros de internamiento, endurece la calificación de infracciones como trabajar sin permiso o no dar de alta al trabajador en la Seguridad Social, aumenta la cuantía de las sanciones económicas para las infracciones, reconoce los derechos fundamentales de los inmigrantes y altera las condiciones de la reunificación familiar. Por otra parte, es clara la importancia de la política de concesión de visados. En España ha funcionado en detrimento evidente de los inmigrantes provenientes de América Latina y ha favorecido a los oriundos del este de Europa, tal y como puso de manifiesto la obligación de visados para determinados colectivos latinoamericanos entre 2002 y 2005.

${ }^{15}$ Según la antedicha Ley 2/2009 (artículo 9), "los extranjeros menores de dieciséis años tienen el derecho y el deber a la educación, que incluye el acceso a una enseñanza básica, gratuita y obligatoria. Los extranjeros menores de dieciocho años también tienen derecho a la enseñanza posobligatoria".
} 
los inmigrantes pueden seguir afluyendo a su destino por la vía de la reagrupación familiar, aun cuando las ventajas laborales se hayan agotado en la sociedad receptora. Sin embargo, aquí es obligado tener presente que la intensidad de la recesión económica actual nos sitúa ante un escenario radicalmente nuevo, que no tiene precedentes en el pasado cercano y que seguramente va a hacer muy difícil, por no decir imposible, repetir aquellas experiencias.

Finalmente, cabe mencionar un último factor que sin duda inhibirá, al menos a corto plazo, la afluencia de inmigrantes a España. No puede ser casual que el estallido inmigratorio español se haya producido en el contexto de una imagen internacional de España muy positiva. Esa imagen con la que se ha estado presentando el país como un lugar económicamente muy dinámico y capaz de ofrecer grandes oportunidades de promoción social, con una gran calidad de vida que ofrecer a sus visitantes foráneos y con fama de acogedor, abierto y tolerante, ha estado sin duda propulsando la afluencia de inmigrantes a nuestro país. Sabemos, por ejemplo, que la imagen de marca de países europeos como España ha tenido una poderosa capacidad de atracción para los jóvenes marroquíes, quienes en proporciones significativamente altas se han estado viendo a sí mismos como emigrantes potenciales en busca de esa tierra de promisión que se les ofrece al otro lado del Mediterráneo (Cebolla y Requena 2010). Es bastante patente que en estos momentos esa imagen favorable y propicia a la recepción de inmigrantes ha quedado anulada, si es que no destruida, por la gravedad de la recesión que atraviesa la economía española y por la titubeante respuesta que hasta el momento hemos sido capaces de darle. Los negativos diferenciales económicos con los países principales de la zona euro están penalizando severamente nuestra reputación internacional, un fenómeno que ha sido amplificado por poderosos medios de comunicación a escala mundial. Por tanto, no se trata sólo de que, hundidos en plena crisis económica, hayamos perdido la aureola de tigre económico, sino que hemos pasado a convertirnos en uno de los enfermos económicos de Europa. Y, como es lógico, con esa imagen no es posible seguir resultando un país atractivo como destino migratorio.

Junto a estos distintos ingredientes que eventualmente podrían atraer nuevos flujos de inmigrantes a nuestro país hay que considerar los factores de expulsión que operan en los países potencialmente emisores, un espacio de la realidad mucho más complejo que, en tanto en cuanto responde a causalidades múltiples, resulta muy difícil de reducir a límites manejables. El primer elemento de inseguridad en las previsiones atañe, desde luego, al futuro económico de las diversas regiones del mundo que han estado enviando emigrantes a nuestro país. Obviamente no es fácil contar con pronósticos fiables del crecimiento económico que van a experimentar los países que han estado alimentando la inmigración española, ni de cómo van a evolucionar sus diferenciales con nuestro país en los próximos años. Es sabido que diversas organizaciones internacionales ${ }^{16}$ ofre-

\footnotetext{
${ }^{16}$ Por ejemplo, el Fondo Monetario Internacional o la Organización para el Desarrollo y la Cooperación Económica.
} 
cen pronósticos detallados del crecimiento del PIB en los diferentes países, pero están sometidos a diversos grados de incertidumbre que, además, se multiplican cuando se pretenden captar los diferenciales entre unos y otros. Por ejemplo, no se puede descartar que algunos de los países que se han comportado como emisores tradicionales de emigrantes entren en dinámicas de crecimiento económico acelerado que podrían rebajar los diferenciales de riqueza con España, reduciendo así los incentivos de sus habitantes para decidirse a moverse a nuestro país. Ahora bien, ¿qué futuro económico concreto les espera a países como Marruecos, Ecuador o Rumania? Otros elementos en origen que pueden llegar a ser muy relevantes para determinar la propensión a emigrar, como la estabilidad política y social o el desarrollo de determinadas políticas migratorias, son aun más difíciles de prever.

Aunque a estas alturas sabemos con precisión que los movimientos migratorios se producen en el contexto de un entramado social con forma de red, y que estas redes tienden a reducir la diversidad de orígenes de los inmigrantes, nada impide que, llegado el momento apropiado, aparezcan en la escena migratoria nuevos protagonistas que, actuando como pioneros, vayan incorporando al país de destino a inmigrantes de procedencias sin tradición migratoria. El caso de los ecuatorianos en España (Reher, Requena y Rosero 2009) es en este sentido paradigmático. Por lo tanto, cabe preguntarse qué nuevos países podrían enviar a nuestro país pioneros con la suficiente fortuna como para dar inicio a una cadena migratoria exitosa. ¿Podrían incorporarse al club de los grandes emisores migratorios nuevos países que hasta ahora no han representado un gran papel en la composición de los flujos de inmigrantes llegados a España? En realidad, no lo sabemos, ni creemos que haya un modo razonable de alcanzar alguna conclusión significativa a este respecto, aunque sin duda haya que contar con esta posibilidad.

Un terreno tal vez un poco más seguro ${ }^{17}$ se pisa cuando se tienen en cuenta las estructuras demográficas que, en combinación con los ciclos económicos, empujan a la población a emigrar. En esta línea, podemos asegurar con un cierto grado de certidumbre que las condiciones demográficas de los países emisores que se han dado en el período del boom migratorio español (1998-2008) van a ser muy diferentes de las que van a regir en los próximos 10015 años. ¿Cómo llegamos a esta conclusión? Básicamente se supone que las poblaciones cuyo crecimiento es muy elevado y no viene acompañado por un crecimiento económico similar o superior, tenderán a experimentar escasez de oportunidades de trabajo. Por lo general, la combinación de esas dos condiciones se considera un factor de expulsión, ya que en dichas circunstancias los niveles de vida tienden a ser más bajos y las expectativas de mejora, menores. De hecho, a lo largo de la historia, las épocas de alto crecimiento de la población han solido ser periodos de migraciones voluminosas. Desde luego, el trasfondo demográfico-económico no es nunca la única causa de las corrientes migratorias, y tal vez ni siquiera la principal, por lo que hay siempre interpretar con cautela los indicadores empíricos que se utilizan.

\footnotetext{
${ }^{17}$ La ganancia en seguridad deriva, a nuestro juicio, de la inercia de las previsiones demográficas.
} 
Generalmente se suele utilizar la tasa de crecimiento de la población en origen. Pero puesto que la interpretación de este indicador se basa casi siempre en las expectativas laborales y en la capacidad que tiene el mercado laboral para absorber la oferta de trabajo, además del hecho de que los emigrantes pertenecen mayoritariamente a esos tramos de edad, aquí hemos preferido utilizar otros dos indicadores, igualmente centrados en la estructura por edades de la población, pero referidos exclusivamente a la que está en edad laboral. A saber: la tasa de crecimiento quinquenal de la población de jóvenes adultos (15-24) y la misma tasa referida a toda la población en edad laboral (15-64).

Utilizando las proyecciones de la ONU para los próximos años y utilizando datos empíricos correspondientes a los últimos 15 años, se puede apreciar el importante cambio de tendencia demográfica que se está dando justo en estos momentos. Entre 1995 y 2005 ó 2010 , las tasas de crecimiento de la población en edad laboral han sido muy superiores a las que se darán de aquí a 2020 ó 2025. Si utilizamos la media de las regiones emisoras a España (fundamentalmente, Europa del Este, África y Sudamérica), el grupo de edad de los jóvenes (15-24 años), que entre 1995 y 2005 creció a una tasa media quinquenal de un $4,5 \%$, pasará a decrecer a una tasa quinquenal negativa de aproximadamente $-4.5 \%$. Utilizando el conjunto de la población en edad laboral (15-64 años), la tasa de crecimiento quinquenal de $7-8 \%$ se va a reducir hasta situarse en el entorno del $4 \%$. Teniendo en cuenta estos datos, se puede decir que está en curso una drástica reducción de la presión demográfica en los mercados laborales de los países emisores.

Este patrón de comportamiento demográfico se va a dar en casi todas las regiones emisoras, pero no por igual. En el Este de Europa, la población de jóvenes adultos apenas ha crecido entre 2000 y 2005. Entre 2005 y 2010 este estancamiento se tornará en un proceso rapidísimo de decrecimiento de alrededor de $-10 \%$ ó $-15 \%$ cada quinquenio. Para el conjunto de estas poblaciones, ha habido estancamiento entre 1995 y 2010, pero a partir de ese momento, los ritmos de reducción va a ser de $-4 \%$ ó $-5 \%$ cada quinquenio. En otras palabras, el escenario previsible para esta región es de clara decadencia demográfica. En Marruecos, tasas de crecimiento quinquenal de los jóvenes de en torno a $6 \%-10 \%$ se tornarán en tasas de declive de alrededor de $-5 \%$ o $-5,5 \%$ a partir de 2010. Para el conjunto de la misma población, las tasas de crecimiento quinquenal de 10\%-14\% vigentes entre 1995 y 2010, se reducirán a un crecimiento de $5 \%$ ó 6\% cada quinquenio. En Sudamérica, a partir de 2005, la población de jóvenes deja de crecer y la del conjunto de la fuerza de trabajo lo hace en torno al $5 \%-6 \%$, un ritmo muy inferior al experimentado antes. La única región emisora donde las tasas de crecimiento de su población en edad laboral son altísimas y prometen seguir siéndolo es el África subsahariana (África Occidental), donde se esperan crecimientos quinquenales de alrededor de $12 \%-14 \%$ en ambas poblaciones (jóvenes y población potencialmente activa).

Se desprende de estos datos que la presión demográfica sobre el mercado laboral en origen, que tanto ha contribuido a disparar el boom migratorio en España, va a disminuir de manera muy significativa en todas las regiones consideradas (salvo en África Occidental). Con la salvedad del este de Europa, ello se debe a que la mayor parte de los países emisores están inmersos en sus propias transiciones demográficas, mucho 
más rápidas e intensas que las históricas que experimentaron los países desarrollados. El resultado de todo ello es que en países como Marruecos, Ecuador o Colombia hace años que el número de nacimientos dejó de crecer y que incluso ha comenzado a disminuir. En consecuencia, el tamaño de los grupos de edades jóvenes en sus poblaciones ha dejado de crecer o está empezando a disminuir. Estos países están, por así decirlo, en una situación similar a aquella en la que se hallaba España hace 20 años. Tal situación terminará por eliminar por completo cualquier presión demográfica sobre el mercado de trabajo en estos países, una de las principales causas durante décadas de buena parte de la pobreza existente en ellos.

El caso de la Europa del Este es bastante diferente, ya que en esa región hace tiempo que dejó de crecer la población en edad laboral, que va camino de sufrir una reducción muy importante. Ello se debe a la bajísima fecundidad que han registrado las mujeres de esta zona desde la caída del llamado telón de acero, ${ }^{18}$ junto a los elevados niveles de mortalidad adulta. A falta de presión demográfica, el flujo continuado de inmigrantes procedentes del Este debe entenderse, sobre todo, en función de la práctica desaparición en los países europeos occidentales de políticas migratorias restrictivas gracias a la ampliación de la UE. Ha sido esa facilidad de movimientos, junto con el evidente deseo de abandonar los territorios en decadencia de la antigua Europa socialista, lo que terminó provocando una avalancha emigratoria en toda la región. Es decir, en este caso la situación demográfica de la zona no parece haber tenido, al menos por ahora, mayor relevancia de cara a la emigración.

Finalmente, merece un breve comentario la región que sí que constituye una reserva emigratoria de gran importancia para Europa y para España. En el África subsahariana la presión demográfica es enorme y promete seguir siéndolo durante mucho tiempo gracias al hecho de que la transición demográfica no ha empezado apenas en esa región. Dicha presión hace incuestionable la importancia de esta reserva migratoria. El hecho de que su efecto en España haya sido, hasta el momento, muy reducido hay que ponerlo en relación con las enormes dificultades y penalidades que estas personas han de pesar para llegar a Europa, además de con el hecho de que las políticas migratorias europeas son muy restrictivas con respecto a este tipo de inmigración. Si llegara un momento en que la importancia de las barreras naturales llegara de alguna manera a disminuir y los costes relativos del traslado se hicieran más asumibles por los mismos inmigrantes, cabría esperar un aluvión de la inmigración subsahariana a nuestro país. Pero, por las razones que hemos mencionado más arriba, no es seguro que ese aluvión vaya a llegar en los próximos años a España.

\footnotetext{
${ }^{18}$ Un buen ejemplo de esta caída de la fecundidad es el caso de Rumanía donde entre 1985-1990 y 1990-1995 el Índice Sintético de Fecundidad pasó de 2,3 a 1,5, y nunca más volvió a subir.
} 


\section{Conclusiones}

En este trabajo hacemos un balance del reciente ciclo migratorio español que de alguna manera sirva de contexto a los trabajos que componen el presente volumen. Para ello hemos decidido situar dicho ciclo entre un panorama histórico de cierta amplitud y una previsión acerca del futuro de las migraciones en nuestro país. Al adoptar esta perspectiva hemos pretendido dos cosas. Primera, resaltar la excepcionalidad del momento migratorio español vivido a comienzos del siglo XXI. Y, segunda, argumentar el en nuestra opinión más que probable agotamiento del ciclo migratorio al que estamos asistiendo en la actualidad.

Vista con cierta perspectiva histórica, la explosión inmigratoria que ha experimentado España en estos últimos años constituye una auténtica singularidad en un país de fuerte y prolongada tradición emigratoria. A lo largo de al menos los últimos ciento cincuenta años nuestro país no ha dejado de participar en importantes oleadas migratorias, tanto interiores como exteriores; en ellas los españoles han actuado sobre todo como emigrantes. Dicho de otro modo, eran los españoles los que dejaban sus lugares de procedencia - sus pueblos, sus regiones o su país - para trasladarse a otras latitudes en busca de una vida y un futuro mejor para sí mismos y sus descendientes. En la segunda mitad del siglo XIX y primeros años del XX hay indicios muy claros de la existencia de una gran oleada emigratoria de carácter doble: una corriente interna, desde los pueblos a las ciudades y desde unas regiones del país a otras; y otra externa, mucho más poderosa, que encontró su destino en el continente americano. Ambas corrientes tuvieron importantes implicaciones sociales, económicas, políticas y culturales tanto para las zonas emisoras como para las receptoras. En todo caso, no sería hasta los años cincuenta del siglo XX cuando el país volviera experimentar oleadas emigratorias de consideración. La presión demográfica sobre los recursos disponibles en el mundo rural, debida al rapidísimo crecimiento de la población durante los quince o veinte años posteriores a la Guerra Civil, provocó una segunda gran oleada migratoria compuesta también de una doble corriente: una interna, intensísima, hacia ciertas regiones y zonas urbanas del país; y otra externa hacia Europa que estuvo acompañada por un flujo bastante más débil dirigido a Sudamérica. Como ya ocurriera como consecuencia de la previa oleada emigratoria, los movimientos masivos de población durante esos dos decenios fueron absolutamente transcendentales para el crecimiento económico y la modernización social del país. El fin de los flujos europeos a raíz de la crisis económica de mediados de los años setenta y el declive paralelo de las migraciones internas marcaron el punto final de uno de los procesos sociales de mayor envergadura experimentados por España en todo el siglo XX, a la vez que pusieron las bases más profundas e importantes del actual proceso migratorio del país.

A esta segunda gran oleada migratoria le suceden casi veinte años de saldos migratorios de escasa relevancia, tras los cuales España comienza a resultar muy interesante como país de destino para cantidades crecientes de inmigrantes procedentes de diversas zonas del mundo. Una serie de factores se combinan para producir una explosión 
inmigratoria que no sólo no tiene precedentes próximos en nuestro país, sino que viene a transformar de forma radical nuestra larga tradición de país expulsor de población: altas tasas de crecimiento económico, gran demanda de puestos de trabajo de baja cualificación, progresivo envejecimiento de la población autóctona y políticas amistosas de admisión e integración confluyen para atraer a un volumen de población inmigrante que sólo puede calificarse de espectacular. Entre 1996 y 2009, el número de inmigrantes se multiplica por seis veces en nuestro país, pasando de representar menos de un $3 \%$ de la población total de España a casi el 14\%. El resultado de esta masiva afluencia de inmigrantes es que España se ha convertido en uno de los destinos favoritos de los inmigrantes internacionales a comienzos del siglo XXI y es hoy uno de los países europeos con mayor proporción de población inmigrada. Por suerte, disponemos de mucha información sobre los principales rasgos de esta corriente inmigratoria: sabemos, por ejemplo, que el grueso de su procedencia, aunque variada, se concentra en unos pocos países (Marruecos, Ecuador, Rumania y algunos países europeos de los que han llegado, sobre todo, ancianos dispuestos a disfrutar en España de su jubilación); que sus zonas de asentamiento favoritas en España han sido los dos archipiélagos, la costa levantina y el centro en torno a Madrid; que su composición por sexos estaba relativamente equilibrada al comienzo del ciclo y se ha ido masculinizando con el tiempo; y que entre ellos predominan las edades jóvenes como corresponde a una inmigración de tipo fundamentalmente económico.

En términos de saldos migratorios absolutos, esta auténtica explosión inmigratoria alcanza su momento culminante en 2007, año a lo largo del cual la población española registró nada menos que 794 mil nuevas entradas. Sin embargo, el examen de las tasas relativas de crecimiento de la población inmigrante revela que el flujo de entradas alcanzó un máximo el año 2000, momento a partir del cual empezó a decrecer (con recuperaciones los años 2004 y 2007). De hecho, la tasa anual de crecimiento de la población inmigrante de 2008 es la más baja desde 1997 y es muy probable que el año 2009 refleje un saldo migratorio muy escaso o próximo a cero. Estos datos hacen pensar, por si solos, en un agotamiento del ciclo expansivo de la inmigración y en un cambio de ciclo, ideas que se refuerzan cuando uno tiene en cuenta el estado de la economía española y su mercado de trabajo. Desde 2007 la economía española comienza a experimentar tasas de crecimiento descendentes que conducen a cifras negativas a partir del segundo trimestre de 2008. Inmersa en una gravísima crisis económica de dimensiones desconocidas en las últimas décadas y de alcance internacional en los países desarrollados, la sociedad española se encamina desde entonces por la senda de la recesión con un resultado muy patente en su mercado de trabajo: a partir del otoño de 2007 la oferta total de puestos de trabajo se contrae en España, habiéndose perdido desde entonces 1,8 millones de empleos. Las consecuencias de la recesión económica para los inmigrantes establecidos en España son muy claras: la masiva destrucción de empleos y el alarmante crecimiento de las tasas de paro han tenido una incidencia especialmente negativa entre la población foránea debido, como se ha señalado antes, tanto al continuado aumento de la población inmigrante activa como a la destrucción de empleo. Además, y 
aunque el provenir económico de los países desarrollados sea incierto en el corto plazo, el balance que a día de hoy puede presentar España en este terreno es muy deficiente. Por lo tanto, incluso sin entrar a considerar el resto de los factores que pueden llegar a hacer atractivo a un país como destino migratorio, es patente que los pobres resultados económicos han destruido la positiva imagen de la que España ha gozado como país de acogida de inmigrantes durante los últimos años.

¿Qué podemos esperar del futuro ahora que la explosión migratoria parece haberse agotado en nuestro país? Hacer pronósticos sobre un fenómeno tan complejo como las migraciones internacionales es tarea muy arriesgada. Muchos son los factores que van a incidir en la cuantía y la dirección de los flujos migratorios en los próximos años, desde el cambio en las estructuras demográficas y las tasas de crecimiento económico de los países en desarrollo que han estado expulsando población hasta los resultados económicos y las realidades institucionales en los países de destino. Con todo, nuestra previsión a este respecto es que un ciclo migratorio tan explosivo como el que hemos experimentado estos últimos años difícilmente volverá a darse en España en el corto o medio plazo. Al margen del momento hoy por hoy incierto en que comience a producirse la recuperación económica y, lo que es más importante, a recuperarse el mercado de trabajo, e incluso teniendo en cuenta que las políticas de admisión e integración no cambiarán de forma decisiva, el factor más seguro en la previsión de los flujos es la evolución demográfica de los países emisores. Aquí el hecho decisivo es que gran parte de los países que hasta el momento han estado enviando población a España van a ver mitigada la presión que hasta ahora han venido ejerciendo sus ciudadanos jóvenes sobre sus propios mercados de trabajo. Es decir, como consecuencia de los procesos de transición demográfica en los que se han adentrado, las estructuras por edad de las poblaciones de los países emisores en el período del boom migratorio español van a ser muy diferentes de las que van a conocer en los próximos años. Con la importante salvedad de los países africanos al sur del Sahara, y con diferentes grados de intensidad, estas nuevas condiciones demográficas se darán en todas las áreas desde las que han llegado inmigrantes a España, incluido Marruecos.

Con esta suerte de síntesis sobre la reciente experiencia migratoria española, el balance de la situación actual y la previsión de futuro deseamos ofrecer al lector del presente número un marco histórico y social amplio en el que pueden encontrar encaje los diferentes trabajos que componen este volumen. Sus distintas contribuciones abordan varias de las más importantes dimensiones del fenómeno migratorio español durante los años del ciclo expansivo a comienzos del siglo XXI. Casi todas ellas basan sus análisis en la información de la Encuesta Nacional de Inmigrantes (2007). Puesto que han pasado ya casi dos años desde que la comunidad investigadora tuvo a su disposición los datos de la Encuesta, se podría pensar que los trabajos que aquí se presentan carecen de atractivo 0 importancia ahora que con toda probabilidad hemos dejado atrás la fase ascendente del ciclo migratorio. Nosotros pensamos, sin embargo, que estas contribuciones no han perdido un ápice de su interés con el cambio de ciclo. En primer lugar, porque muchas de ellas tratan aspectos más o menos estructurales que constituyen regularidades de la vida de las comunidades de inmigrantes destinadas a reproducirse en otras coyunturas o momentos 
migratorios. En segundo lugar, porque en todo caso dejan testimonio de lo que ha sucedido en un momento singular de la historia migratoria de nuestro país que no encuentra parangón en el pasado reciente. Y, en tercer lugar, porque el conocimiento acumulado en esta materia suministra, sin duda, criterios informados para afrontar de manera razonable los posibles problemas que habremos de afrontar en el futuro.

\section{Referencias Bibliográficas}

Aja, E., J. Arango y J. Oliver. dir. 2008. La inmigración en la encrucijada. Anuario de la inmigración en España. Barcelona: Fundació CIDOB.

Aja, E., J. Arango y J. Oliver. eds. 2009. La inmigración en tiempos de crisis. Anuario de la inmigración en España. Barcelona: Fundació CIDOB.

Alloza, M., B. Anghel y P. Vázquez. 2009. “¿Seguirán llegando inmigrantes a España”. Pp. 110-126 en E. Aja, J. Arango y J. Oliver (eds.) La inmigración en tiempos de crisis. Anuario de la inmigración en España. Barcelona: Fundació CIDOB.

Arango, J. 1985. "Las 'leyes de las migraciones' de E. G. Ravenstein, cien años después." Revista Española de Investigaciones Sociológicas 32: 7-26.

Arango, J. 2009. "Después del gran boom: la inmigraciuón en la bisagra del cambio." Pp. 52-73 en E. Aja, J. Arango y J. Oliver (eds.) La inmigración en tiempos de crisis. Anuario de la inmigración en España. Barcelona: Fundació CIDOB.

Baines, D. 1991. Emigration from Europe 1815-1930. Studies in Economic and Social History. Londres: MacMillan.

Cebolla, H. y M. Requena 2010. "Marroquíes en España, Holanda y Francia: ¿importa el modelo de gestión de la diversidad para explicar la integración?." Historia y Política 23:55-83.

Domingo, A. y J. Recaño 2007. "Perfil demográfico de la población extranjera en España." Pp. 20-43 en E. Aja y J. Arango. eds., La inmigración en España en 2006. Anuario de inmigración y políticas de inmigración. Barcelona: CIDOB Edicions, Edicions Bellaterra.

Finotelli, C. 2007. "Italia, España y el modelo migratorio mediterráneo en el siglo XXl", Análisis del Real Instituto Elcano. Madrid: Real Instituto Elcano.

González, F. y B. Echeverri 2009. "Los inmigrantes colombianos en España”. Pp. 153-184 en D.-S. Reher y M. Requena (eds.), Las múltiples caras de la inmigración en España. Madrid: Alianza.

Hirschman CH., PH. Kasinitz y J. De Wind. eds. 1999. The Handbook of International Migration. Nueva York: Russell Sage.

López De Lera, D. 2006. "Panorama de la inmigración". Pp. 17-71 en A. Izquierdo. ed. Demografía de los extranjeros: incidencia en el crecimiento de la población. Bilbao: Fundación BBVA. 
Martínez Carrión, J. M. 2002. El nivel de vida en la España rural, siglos XVIII-XX. San Vicente del Raspeig: Universidad de Alicante.

Massey D.S., J. Arango, G. Hugo, A. Kouachi, A. Pellegrino y J.E. Taylor. 2002. Worlds in Motion: Understanding International Migration at the end of the Millennium. Oxford: Clarendon Press.

Oliver, J. 2009. "Inmigración y crisis del mercado de trabajo en España 2008-209. El fuerte aumento del desempleo de la inmigración y sus razones". Pp. 74-108 en E. Aja, J. Arango y J. Oliver (eds.), La inmigración en tiempos de crisis. Anuario de la inmigración en España. Barcelona: Fundació CIDOB.

Reher, D.S. 1994. "Ciudades, procesos de urbanización y sistemas urbanos en la península ibérica, 1550-1991", pp. 1-30 en M. Guàrdia, F.J. Monclús y J.L. Oyón (eds.), Atlas Histórico de las ciudades europeas. Península Ibérica, Salvat-Centre de Cultura Contemporàni de Barcelona: Barcelona.

Reher, D.S., L. Cortés, F. González, M. Requena, M.I. Sánchez, A. Sanz y M. Stanek. 2008. Informe Encuesta Nacional de Inmigrantes (ENI-2007). Madrid: Instituto Nacional de Estadística.

Reher, D.S. y M. Requena. 2008. "El cuestionario de la Encuesta Nacional de Inmigrantes 2007." Índice. Revista de Estadística y Sociedad 30:13-15.

Reher, D.S. y M. Requena. 2009a. "The National Immigrant Survey of Spain: A new data source for migration studies in Europe." Demographic Research 20: 253-278.

Reher, D.S. y M. Requena. eds. 2009b. Las múltiples caras de la inmigración en España. Madrid: Alianza.

Reher, D.S., M. Requena y L. Rosero-Bixby. 2009. “Ecuatorianos en España”. Pp. 117-152 en D. Reher y M. Requena (eds.), Las múltiples caras de la emigración en España. Madrid: Alianza.

Reher, D.S. y B. Sanchez Alonso. 2009. "Argentina y España: Siglo y medio de intercambios migratorios'. Pp. 77-116 en D. Reher y M. Requena (eds.), Las múltiples caras de la emigración en España. Madrid: Alianza.

Requena, M. y D.S. Reher. 2009. "La reciente experiencia inmigratoria en España". Pp. 289-321 en D. Reher y M. Requena. eds. Las múltiples caras de la inmigración en España. Madrid: Alianza.

Sánchez Alonso, B. 1995. Las causas de la emigración española 1880-1930. Madrid: Alianza.

Sanchez Alonso, B. 2000a. "European emigration in the late nineteenth century: the paradoxical case of Spain." Economic History Review 53: 309-330

Sanchez Alonso, B. 2000b "Those who left and those who stayed behind: explaining emigration from the regions of Spain, 1880-1914." Journal of Economic History 60: 730-755.

Silvestre, J. 2005. "Internal migrations in Spain." European Review of Economic History 9: 233-265.

Stanek, M. 2009. "Los inmigrantes rumanos y búlgaros en España: perfiles sociodemográficos y pautas migratorias". Pp. 217-250 en Reher, D. y M. Requena M. eds. Las múltiples caras de la inmigración en España. Madrid: Alianza. 
DAVID REHER es Catedrático de Sociología en el Departamento de Sociología II de la Universidad Complutense de Madrid. Ha sido fundador, vicepresidente y presidente de la Asociación de Demografía Histórica, presidente del comité de demografía histórica de la IUSSP, Director del GEPS e Investigador Principal del equipo promotor de la Encuesta Nacional de Inmigrantes 2007. Cuenta con numerosos libros, capítulos de libros y artículos científicos en los campos de la demografía, la historia de la población y la historia de la familia.

MIGUEL REQUENA es Catedrático de Sociología en el Departamento de Sociología II (Estructura Social) en la UNED y miembro del Grupo de Estudios 'Población y Sociedad'. Ha sido profesor en la Universidad Complutense, miembro del Gabinete Técnico del Centro de Investigaciones Sociológicas, Doctor Vinculado al Instituto de Estudios Sociales Avanzados del Consejo Superior de Investigaciones Científicas, Senior Associate Member en St. Antony College (Oxford) y Visiting Professor en Princeton University. Su investigación se ha centrado en la sociología y la demografía de la familia, la sociología de la edad, la sociología de la estructura y la estratificación social y los procesos contemporáneos de cambio social.

ALBERTO SANZ es Profesor titular en la Universidad Complutense de Madrid y miembro del Grupo de Estudios "Población y Sociedad" (GEPS). Sus trabajos analizan temas como la mortalidad en la infancia y las trayectorias vitales de individuos y sus familias. También ha trabajado sobre las migraciones, participando en el diseño y explotación de la Encuesta Nacional de Inmigrantes.

RECIBIDO: 22/03/2010

ACEPTADO: 05/09/2010 